\title{
V-AI-O catalysts prepared by flame pyrolysis for the oxidative dehydrogenation of propane to propene
}

I. Rossettia , L. Fabbrini ${ }^{a}$, N. Ballarini ${ }^{b}$, C. Oliva ${ }^{a}$, F. Cavani ${ }^{*}$, A. Cericola ${ }^{b}$, B. Bonellic ${ }^{c}$, M. Piumetti c $^{\text {, E. Garrone }}{ }^{c}$, H. Dyrbeck ${ }^{d}$, E.A. Blekkan ${ }^{d}$, L. Fornia ${ }^{a}$

aDip. CFE e ISTM-CNR, Università di Milano, via C.Golgi, 1920133 Milano (Italy)

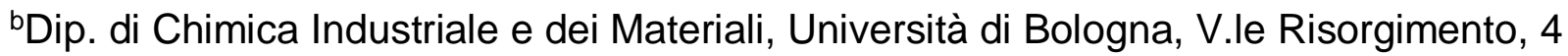
40136 Bologna. INSTM, Research Unit of Bologna, NoE Idecat partner (FP6 of EU). ${ }^{\mathrm{C}}$ Dipartimento di Scienza dei Materiali ed Ingegneria Chimica, Politecnico di Torino, C.so Duca degli Abruzzi 24, I-10129, Torino, Italy. INSTM, Torino Politecnico Research Unit. ${ }^{d}$ Department of Chemical Engineering, Norwegian University of Science and Technology (NTNU), N-7491 Trondheim, Norway

\section{Abstract}

A flame pyrolysis (FP) procedure has been set up for the preparation of $\mathrm{V} / \mathrm{Al} / \mathrm{O}$ catalysts to be employed for the oxidative dehydrogenation of propane to propylene. The samples have been characterised by means of various techniques (FT-IR, Raman, EPR, ICP-MS, TGA, XRD, SEM) and their catalytic activity has been evaluated in two different operating modes, i.e. under anaerobic conditions and by co-feeding oxygen. The particle size distribution became progressively more homogeneous with increasing $\mathrm{V}$ concentration, due to the catalytic effect of the $\mathrm{V}$ ions during the FP synthesis. Some $\mathrm{V}_{2} \mathrm{O}_{5}$ segregation was observed even at low $\mathrm{V}$ loading. However, higher $\mathrm{V}$ dispersion was attained with respect to a reference sample prepared by impregnation of the FP-prepared alumina support. 
The increase of $\mathrm{V}$ concentration always led to an improvement of propane conversion, though selectivity showed different trends depending on the operating conditions. The comparison with the sample prepared by impregnation showed similar catalytic activity, with a bit higher selectivity for the FP-prepared sample under anaerobic conditions.

Keywords: Oxidative dehydrogenation of propane; flame-pyrolysis; vanadium-aluminium oxides catalysts.

+) Corresponding author, Fax +39-051-2093680, e-mail: fabrizio.cavani@unibo.it 


\section{INTRODUCTION}

Oxidative dehydrogenation (ODH) of light alkanes offers an attractive route to the corresponding alkenes, the thermodynamic constraints of non-oxidative routes being avoided. The yield of alkenes by ODH on most catalysts can be limited by parallel and consecutive reactions, mainly the combustion of reactant and products to $\mathrm{CO}$ and $\mathrm{CO}_{2}$ [1], and the co-feeding of oxygen may introduce a safety concern, which however can be satisfactorily faced, together with selectivity improvement, by proper catalyst formulation and process engineering.

Among the several possible active phases $\mathrm{V}$ oxide $\left(\mathrm{VO}_{\mathrm{x}}\right)$ is the most investigated and, when loaded in proper amount on a suitable support, it leads to promising ethylene [1-5], propylene [1,2,6,7] and butenes [3] yields. Many different oxides have been proposed as supports, such as $\mathrm{ZrO}_{2}$ [8,9], $\mathrm{TiO}_{2}$ [7], V-substituted zeolites or silicalites [10], $\mathrm{SiO}_{2}[4,8,11]$ and $\mathrm{Al}_{2} \mathrm{O}_{3}$, usually as the $\gamma$-isomorph [1-3,5-8]. Most of these papers deal with the effect of $\mathrm{V}$ loading in determining the species active for the reaction and with the role of the support on $V$ surface dispersion. Furthermore, support acidity can adversely affect catalyst selectivity when low $\mathrm{V}$ loading leaves uncovered Lewis acid sites, especially in the case of alumina-supported samples. However, $\mathrm{V}_{2} \mathrm{O}_{5}$ segregation is usually observed at high V loading, sometimes accompanied by the formation of the $\mathrm{AlVO}_{4}$ phase $[12,13]$. High activity is ascribed to vanadate species up to the formation of a $\mathrm{VO}_{\mathrm{x}}$ monolayer, while lower activity is usually associated with the presence of $\mathrm{V}_{2} \mathrm{O}_{5}$ and $\mathrm{AlVO}_{4}$ phases [13] and high selectivity can be achieved when a $\mathrm{VO}_{x}$ monolayer completely covers the support.

The catalysts so far described are usually prepared by impregnation of preformed commercial supports. A new procedure based on flame-pyrolysis (FP) of an organic solution of metal ion precursors has been set up recently for the preparation of different single or mixed oxides in nanoparticle powder form [14-21]. This procedure has been selected for the preparation of a set of $\mathrm{V}-\mathrm{Si}-\mathrm{O}$ catalysts for the ODH of propane, leading to 
interesting results about the effect of both the nature of $\mathrm{Si}$ oxide and the preparation method on catalyst performance [11]. The aim of the present work was then to apply the FP method to prepare a set of nanoparticle $\mathrm{V}-\mathrm{Al}-\mathrm{O}$ catalysts, characterised by different $\mathrm{V}$ loading, and to evaluate their behaviour, particularly in comparison with the previous $\mathrm{V}$-SiO samples. A sample of $\mathrm{AlVO}_{4}$ has been also prepared for further comparison purposes, as well as a sample prepared by impregnation of $\mathrm{V}$ on a FP-prepared $\mathrm{Al}_{2} \mathrm{O}_{3}$ support. All of the samples have been characterised by different physical-chemical techniques and their activity has been compared under different reaction conditions, namely either by cofeeding propane and air (aerobic oxidation) or by feeding alternatively the substrate and the oxidising agent (anaerobic oxidation).

\section{2 - EXPERIMENTAL}

\section{1 - Catalysts preparation}

A detailed description of the FP preparation procedure and of the effect of the main operating parameters on catalyst properties can be found elsewhere [15-18]. Briefly, proper amounts of precursor salts were dissolved in an organic solvent, so to obtain a 0.1 $0.2 \mathrm{M}$ solution (concentration referred to the nominal oxide composition). The prepared solution $\left(4.4 \mathrm{~cm}^{3} / \mathrm{min}\right)$, together with $5 \mathrm{~L} / \mathrm{min}$ of oxygen (SIAD, purity $>99.95 \%$ ), was fed to the FP burner. The main flame was ignited and supported by a ring of twelve premixed $\mathrm{O}_{2}$ $+\mathrm{CH}_{4}$ flamelets. The catalyst powder so produced was collected by means of a $10 \mathrm{kV}$ electrostatic precipitator $[15,22]$.

Two Al precursors have been tested, the nitrate and the isopropoxide, whereas $\mathrm{V}$ oxi-acetyl-acetonate has been selected as $\mathrm{V}$ precursor. In addition, different solvents have been tested: linear alcohols (C1-C8) and (C1-C3) carboxylic acids. The preparation yield was $90-95$ wt\% with respect to the precursor salts for each sample. The composition of the 
samples is given in Table 1 . The comparative catalyst (V10Al-i, Table 1) was made by impregnation of the FP-prepared $\mathrm{Al}_{2} \mathrm{O}_{3}$ sample with a $\mathrm{NH}_{4} \mathrm{VO}_{3}$ solution, followed by drying and calcination at $700^{\circ} \mathrm{C}$ in air.

\section{2 - Catalysts characterisation}

Specific surface area (SSA) was measured by $\mathrm{N}_{2}$ adsorption/desorption at $77 \mathrm{~K}$ on a Micromeritics ASAP 2010 apparatus. Morphological analysis was done by a LEICA LEO 1430 scanning electron microscope (SEM). XRD analysis was made by means of a Philips PW1820 powder diffractometer, by using the Ni-filtered Cu K $\alpha$ radiation $(\lambda=1.5148 \AA)$. The diffractograms obtained were compared with literature data for phase recognition [23]. Thermogravimetric analysis (TGA) of the as prepared powder was carried out in flowing air by means of a Perkin-Elmer TGA7 apparatus. Catalyst composition has been determined by ICP-MS (Perkin Elmer, ELAN5500) after microwave digestion of the sample in 10 vol\% $\mathrm{HNO}_{3}$. Electron magnetic resonance (EPR) spectra were collected between 120 and 300 $\mathrm{K}$ with a Bruker Elexsys instrument, equipped with a standard rectangular ER4102ST cavity and operated at X band, $6.23 \mathrm{~mW}$ microwave power, and $3 \mathrm{G}$ modulating amplitude. The microwave frequency was measured with a HP 5340A frequency counter. Spectral simulations, when required, were done by means of the Bruker SimFonia programme. Raman spectra were collected on a Micro-Raman (Renishaw) system, equipped with $\mathrm{Ar}$ laser $(514.5 \mathrm{~nm})$ source. For FT-IR measurements, powder samples were pressed into thin, self-supporting wafers and pre-treated in high vacuum (residual pressure $<10^{-3}$ mbar) using a standard vacuum frame, in a IR cell equipped with $\mathrm{KBr}$ windows. Spectra were collected at $2 \mathrm{~cm}^{-1}$ resolution, on a Bruker FTIR Equinox 55 spectrophotometer equipped with MCT detector. To remove moisture and other atmospheric contaminants wafers were outgassed for 1 hour at 150,300 and $500^{\circ} \mathrm{C}$ before adsorption of $\mathrm{NH}_{3}$, which has been 
dosed at r.t., within $0.01-23.0$ mbar equilibrium pressure range. After each experiment an evacuation step has been performed, to investigate the reversibility of the interaction.

\section{3- Catalytic activity tests}

Catalytic activity was measured by means of a continuous, quartz tubular reactor (i.d. $=7 \mathrm{~mm})$. The catalyst $(0.5-0.6 \mathrm{~g}, 425-600 \mu \mathrm{m}$ particle size $)$ was activated prior to each run in $20 \mathrm{~cm}^{3} / \mathrm{min}$ flowing air, while increasing temperature up to $600^{\circ} \mathrm{C}$, then kept for 30 $\min$. The flow rate of the reactants mixture for the co-feeding mode tests was $11 \mathrm{~cm}^{3} / \mathrm{min}$ of $\mathrm{C}_{3} \mathrm{H}_{8}(20 \mathrm{~mol} \%)+11 \mathrm{~cm}^{3} / \mathrm{min}$ of $\mathrm{O}_{2}(20 \mathrm{~mol} \%)+28 \mathrm{~cm}^{3} / \mathrm{min}$ of $\mathrm{He}+4 \mathrm{~cm}^{3} / \mathrm{min}$ of $\mathrm{N}_{2}$ (60 mol\% inert gases). For the anaerobic mode flow rates were $6 \mathrm{~cm}^{3} / \mathrm{min}$ of $\mathrm{C}_{3} \mathrm{H}_{8}$ (22 $\mathrm{mol} \%)+19 \mathrm{~cm}^{3} / \mathrm{min}$ of $\mathrm{He}+2 \mathrm{~cm}^{3} / \mathrm{min}$ of $\mathrm{N}_{2}$. Contact time was $1 \mathrm{~s}$ for the former and $2 \mathrm{~s}$ for the latter testing mode. The out coming gas was analysed by means of a micro-GC (Agilent 3000A), equipped with Plot-Q, OV-1 and MS-5A columns for full detection of the effluent products.

\section{3 - RESULTS AND DISCUSSION}

\section{1 - Catalyst preparation and characterisation}

On the basis of the solubility tests, the best solvent for the $\mathrm{V}$ precursor was found to be ethanol, which provided suitable solubility for $\mathrm{Al}\left(\mathrm{NO}_{3}\right)_{3}$ as well. By contrast, $\mathrm{Al}$ isopropoxide showed poor solubility in any of the solvents tried. A preliminary TGA analysis in air of $\mathrm{Al}\left(\mathrm{NO}_{3}\right)_{3}$ showed a one-step decomposition mechanism, ensuring nitrate transformation into the oxide at $\mathrm{ca} .200^{\circ} \mathrm{C}$. In order to modify the flame temperature during catalyst preparation and to achieve a less rapid evaporation of the fuel, an equal volume of 1-octanol has been added after dissolution of the precursors into ethanol. 
During the FP synthesis a complete combustion of the organic species (solvent and counterions) should be achieved, with the simultaneous formation of the desired oxide phase. Nevertheless, some unburnt carbonaceous residua are usually found. Their quantification was done by TGA analysis in flowing air and the results are given in Table 2 . At low $\mathrm{V}$ content the low temperature peak (attributed to residual solvent) was always larger than the high temperature one. Furthermore, the latter peak attributed to residual high $\mathrm{C} / \mathrm{H}$ species or to carbonate like compounds, shifted towards lower temperature with increasing $\mathrm{V}$ loading. This is in line with the hypothesis that the presence of a catalytically active V-based phase for oxidation reactions during catalyst preparation by FP facilitates precursor decomposition [11].

The overall crystallinity of the present samples was low, due to their nanoparticle powder form and it progressively decreased with increasing $V$ loading (Fig.1a). Phase identification was obtained when possible by comparison with literature data. $\mathrm{Al}_{2} \mathrm{O}_{3}[23$, file 004-0875] was always accompanied by different $\mathrm{V}$-containing species, even at the lowest V-loading. However, unambiguous attribution of the $\mathrm{VO}_{\mathrm{x}}$ phases was impossible, due to peak broadening and overlapping. The most reliable comparison has been made with orthorhombic $\mathrm{V}_{2} \mathrm{O}_{5}$ [23, file 009-0387].

The reference sample of FP-prepared $\mathrm{Al}_{2} \mathrm{O}_{3}$ was calcined at $600^{\circ} \mathrm{C}$ for $24 \mathrm{~h}$. TGA analysis (Table 2) showed that this sample was cleaned up quite completely from carbonaceous residua and XRD confirmed that it was constituted by pure tetragonal $\delta$ $\mathrm{Al}_{2} \mathrm{O}_{3}$ [23, file 046-1131] (Fig.1a). The as prepared sample with nominal composition $\mathrm{AlVO}_{4}$ was partly amorphous and the typical reflections of this phase [23, file 039-0276] appeared only after calcination at $600^{\circ} \mathrm{C}$ for $1 \mathrm{~h}$. Even in that case, however, a small fraction of $\mathrm{V}_{2} \mathrm{O}_{5}$ was still present [23, file 009-0387] (Fig.1b).

It is worth noting that with the samples containing less vanadium oxide, a postsynthesis calcination treatment did not cause any change in the XRD pattern. This 
suggests that the higher amount of $\mathrm{V}\left(\mathrm{AlVO}_{4}\right)$, the longer is the residence time in the flame needed for obtaining stable compounds, especially when preparing a mixed oxide. Due to this, the sample was pre-calcined at $600^{\circ} \mathrm{C}$ before catalyst testing and characterisation.

Typical SEM pictures of the present samples are collected in Fig.2. Low uniformity of particle size can be observed: very small nanospheres seems to coalesce into much bigger particles, whose size spreads through orders of magnitude. However, better homogeneity and smaller particle size were obtained with increasing $\mathrm{V}$ loading. The best results were observed with the $\mathrm{AIVO}_{4}$ sample, which consisted of uniform spheroids with a diameter of ca. $100 \mathrm{~nm}$.

The present results are partly due to the solvent nature. Indeed, alcohols did not provide small and homogeneous particle size also for different catalyst compositions $[17,18]$. However, the increase of particle size uniformity with $\mathrm{V}$ loading seems to confirm the beneficial effect of this element during catalyst preparation. It can be hypothesised that its oxidation activity allows a better and more uniform precursors decomposition at lower temperature, thus leading to a better size homogeneity.

Table 1 shows that all the samples possess a relatively low SSA, comparable with what reported elsewhere for different samples prepared from alcohols as solvents $[17,18]$, that typically possess surface area of ca. $20-30 \mathrm{~m}^{2} / \mathrm{g}$. Higher SSA is expected when carboxylic acids are employed, due to a bit lower flame temperature, but mainly to their decomposition route. The latter, indeed, involves acids decarboxylation with formation of a low-boiling alkane, which allows further fragmentation of the forming particles during solvent flash [24].

\section{2-EPR analysis}

The EPR spectrum obtained at room temperature with sample V10Al is shown in the inset of Fig.3 together with its simulation, obtained with the parameters reported in 
Table 3. A second ca. $9 \mathrm{G}$ narrow line (indicated by an arrow in Fig.3) overlaps the main pattern in its central region. A further EPR investigation on the $\mathrm{Al}_{2} \mathrm{O}_{3}$ substrate allowed us to attribute this narrow line to E' point defects $[25,26]$. Sample V10Al-i, with the same nominal composition, but prepared by impregnation on the $\mathrm{Al}_{2} \mathrm{O}_{3}$ sample, showed a further very intense FMR1 feature between ca. 0 and $1500 \mathrm{G}$ (Fig.3b). The spectral profile changed markedly also with increasing $\mathrm{VO}_{x}$ concentration. Indeed, its resolution decreased with sample V25Al, whereas further intense FMR1 features and a FMR2 band appeared in the range between ca. 0 and $1500 \mathrm{G}$ and at ca. $2900 \mathrm{G}$, respectively (Fig.4a). A similar behaviour was observed with sample V50AI. By contrast, a very intense but less resolved pattern of isolated $\mathrm{V}^{4+}$ ions was recorded with the $\mathrm{AlVO}_{4}$ sample (Fig.5a).

After reaction carried on in the co-feed mode (vide infra), the intensity of the EPR and the FMR patterns generally decreased for all samples (Fig.4b). By contrast, after reaction carried out under anaerobic conditions the intensity of the EPR spectrum increased with V10Al sample, but this did not occur with the other catalysts. Indeed, only a very intense Lorentzian-shaped line appeared with them, characterised by $g \cong 1.97$ and peak-to-peak linewidth of ca. $150 \mathrm{G}$ (Fig.5b).

\subsection{1 - Nature of the $V^{4+}$ paramagnetic species}

The EPR spectrum reported in Fig. $3 a$ and in its inset is typical of $V^{4+}$ ions, though it differs markedly (see Table 3) from those reported elsewhere for V-Si-O [11]. In the latter case the EPR spectral profile was independent of $\mathrm{V}_{2} \mathrm{O}_{5}$ concentration and only an increase of intensity was observed with increasing $V$ loading, in contract to the present case (compare Fig.3a with Fig.4a). Only the V10Al sample provided spectra resolved enough to be simulated. An EPR line width of ca. $50 \mathrm{G}$, as in this case, was also reported with pure $\mathrm{V}_{2} \mathrm{O}_{5}$ [27]. However, those lines were Gaussian-shaped, suggesting the presence of static 
disorder. In contrast, the EPR lines reported here are always Lorentzian-shaped, with both V-Si-O [11] and V-Al-O, indicating homogeneous line broadening in both cases. However, the EPR lines were by far narrower with V-Si-O than with V-Al-O (see Table 3) suggesting the presence, in the latter case, of more efficient spin relaxation processes among interacting spins. Indeed, spin-spin interactions became even more evident at higher concentration of $\mathrm{V}$, forming $\mathrm{V}^{4+}$-based ferromagnetic clusters (Fig.4a) (vide infra). The fact that no FMR band was noticed with the calcined $\mathrm{AlVO}_{4}$ sample (Fig.5a), in spite of ca. $70 \% \mathrm{~V}$ concentration, can be explained by assuming that in this sample $\mathrm{V}^{4+}$ ions occupy crystal sites, forming a mixed oxide with $\mathrm{Al}$, so that no magnetic clusters can form from $\mathrm{V}$ $\mathrm{V}$ interaction. However, the $\mathrm{V}^{4+}$ ions should interact at least in part with each other also in this sample, as revealed by the broadening of the spectral lines.

Reciprocally interacting $\mathrm{V}^{4+}$ ions are observed also after reaction carried out under anaerobic conditions over V10Al. Indeed, an increased spectral intensity accompanied by a decreased resolution is observed in this case.

A completely different behaviour is shown by the spent catalysts containing higher amounts of $\mathrm{VO}_{x}$ (vide infra). On the contrary, the intensity of both EPR and FMR spectra decreased after tests in the co-feed mode (Fig.4b), indicating that both paramagnetic and ferromagnetic $\mathrm{V}^{4+}$-based species are involved in this process.

The actual location of $\mathrm{V}^{4+}$ ions in host lattices has been the subject of controversial debates for many systems [28-37] including $\mathrm{V}_{2} \mathrm{O}_{5}$ supported on inert oxides like $\mathrm{Al}_{2} \mathrm{O}_{3}$ and $\mathrm{SiO}_{2}[27,38,39]$. Small hyperfine parameters [30], by far smaller than those given in Table 3 , are typical of a tetrahedral site (low co-ordination number), whereas large hyperfine parameters were attributed to a dodecahedral site (high co-ordination number), i.e. to a more ionic bond [40]. Furthermore, the disappearance of that EPR pattern at $\mathrm{T}>20 \mathrm{~K}$ $[30,38,39]$ was in line with the presence of dynamic Jahn-Teller exchange, introducing lowlying excited vibronic states which would favour fast spin relaxation mechanisms in $\mathrm{V}^{4+}$. 
Therefore, in those cases $\mathrm{V}^{4+}$ would be localised in distorted octahedrons or tetrahedrons of surrounding oxygen atoms $[30,38,39]$.

However, in other cases $[27,39]$ the EPR spectra were detectable at least up to room temperature and were characterised by $g_{/ /}<g_{\perp}$, as in the present case and in our previous $\mathrm{V}$-Si-O samples [11]. This was attributed to tetragonal distortion occurring in surface vanadyl species in average $\mathrm{C}_{4 \mathrm{v}}$ symmetry. The latter was attributed to four oxygen ligands forming a square parallel to the surface and to a $\mathrm{V}=\mathrm{O}$ bond perpendicular to it.

It has been reported [27] that in similar cases an increased value of the parameter

$$
B=\left(g_{/ /}-g_{\mathrm{e}}\right) /\left(g_{\perp}-g_{\mathrm{e}}\right)
$$

indicates either a shortening of the $\mathrm{V}=\mathrm{O}$ bond or an increased distance of the four oxygen ligands in the basal plane, both these situations indicating a strengthening of the $V=O$ bond. Therefore, if the $\mathrm{V}=\mathrm{O}$ bond strength can be correlated to catalytic activity as an index of oxygen availability from the catalyst, then $B$ can be used to interpret activity data. Unfortunately, $B$ was evaluated only with sample V10Al, since the EPR spectra were characterised by low resolution at higher $\mathrm{V}$ loading, in contrast to what is reported elsewhere with V-Si-O. Hence, the only possible comparison was between sample V10Al and V-Si-O samples [11]. We observed that $B(\mathrm{~V} 10 \mathrm{Al})=1.47 \ll B(\mathrm{~V} 10 \mathrm{Si})=3.60$. Accordingly, the data reported in [27] for samples similar to the present ones, but prepared by a different procedure, lead to $B^{\prime}(\mathrm{Al})=2.14<B^{\prime}(\mathrm{Si})=2.43$.

\subsection{2 - Nature of the ferromagnetic species}

When added to the support by impregnation, $\mathrm{V}$ remains mainly on the surface of the sample. Therefore, surface $\mathrm{V}^{4+}$-based ferromagnetic domains can form even at low vanadium concentration, as revealed by the very intense FMR1 band observed with the V10Al-i sample (Fig.3b). Greater amounts of $\mathrm{V}$ are needed to create ferromagnetic 
domains in samples where metal ions are dispersed also in the bulk, as in our FPprepared catalysts (e.g., Fig.4a).

At last, the Lorentzian-shaped line observed after testing under anaerobic conditions with samples characterised by high V loading, i.e. with V25AI, V50Al and $\mathrm{AIVO}_{4}$, suggests that in these cases the greater amount of available $\mathrm{V}^{4+}$ organizes into strongly correlated clusters perhaps forming superparamagnetic particles.

\section{3 - FT-IR and Raman analysis}

Raman spectra of samples (not reported) were all similar, showing weak signals ascribable to crystalline $\mathrm{V}_{2} \mathrm{O}_{5}\left(285,307,406,482,528,702\right.$ and $\left.996 \mathrm{~cm}^{-1}\right)[2,41]$. Spectra of samples V10Al and V25Al show two additional, though weak, bands at 351 and 1014 $\mathrm{cm}^{-1}$ (asterisks), due to $\mathrm{VO}_{x}$ and to isolated $\mathrm{V}=\mathrm{O}$ species, respectively $[2,41]$. Signals were also present in the $750-1000 \mathrm{~cm}^{-1}$ range, assigned in the literature to $\mathrm{V}-\mathrm{O}-\mathrm{V}$ stretching mode of poly-vanadate species [42] and to V-O-Al groups formed after interaction of vanadium with the $\mathrm{Al}_{2} \mathrm{O}_{3}$ support [43]. As a whole, $\mathrm{VO}_{x}$ and isolated $\mathrm{V}=\mathrm{O}$ species are present when vanadium content does not exceed $25 \%$ by weight, but even at low vanadium content formation of crystalline vanadia may occur.

Fig.6 reports hydroxyls spectra of samples $\mathrm{Al}_{2} \mathrm{O}_{3}, \mathrm{~V} 10 \mathrm{Al}$, V50Al and V10Al-i (inset) previously outgassed at $150^{\circ} \mathrm{C}$ for $1 \mathrm{~h}$, in order to remove moisture and other contaminants. The spectrum of the FP-prepared support (curve a) shows the typical bands of hydroxyls normally occurring at the surface of $\mathrm{Al}_{2} \mathrm{O}_{3}$, at 3739 and $3700 \mathrm{~cm}^{-1}$, readily assigned to $\mathrm{OH}$ bonded to octahedral aluminium ions and to bridged hydroxyls, respectively [43]. The broad absorption observed at lower wavenumbers is due to other hydroxyls interacting via $\mathrm{H}$-bonding. The latter species are removed after evacuation at $500^{\circ} \mathrm{C}$ (not reported). 
The FP-prepared samples (curves $b$ and $c$ ) show very noisy hydroxyls spectra, probably due to the presence of $\mathrm{VO}_{\mathrm{x}}$ species covering the surface. In fact their transparency decreases at higher temperatures. The sample prepared by impregnation (inset to Figure) shows a broad absorption between 3600 and $3400 \mathrm{~cm}^{-1}$, due to a higher hydroxyls population, probably due to the different preparation procedure.

The presence of Brønsted sites like $\mathrm{V}-\mathrm{OH}$ species cannot be detected from the hydroxyls spectra as such and hence ammonia has been used as probe. $\mathrm{NH}_{3}$ has been dosed on samples previously outgassed at 150 and $300^{\circ} \mathrm{C}$. When outgassed at higher temperature, i.e. $500^{\circ} \mathrm{C}$, samples transparency was too poor to allow $\mathrm{FT}$-IR spectra recording, presumably due to the presence of crystalline vanadia, undergoing partial reduction after thermal treatment in vacuo.

Fig.7 reports the difference spectra in the $1800-1150 \mathrm{~cm}^{-1}$ range, recorded after dosage of ammonia on sample V50Al, previously outgassed at $150^{\circ} \mathrm{C}$ (Section a) and $300^{\circ} \mathrm{C}$ (Section b). A main band at $1423 \mathrm{~cm}^{-1}$ was observed, due to the bending vibration of ammonium ions [44], formed upon interaction with Brønsted sites, i.e. $\mathrm{V}-\mathrm{OH}$ species at the surface of the $\mathrm{V}_{2} \mathrm{O}_{5}$ phase detected by Raman spectroscopy. This assignment is based on the fact that dosage of ammonia on the $\mathrm{Al}_{2} \mathrm{O}_{3}$ prepared by FP did not show the irreversible formation of ammonium ions, the $\mathrm{AlOH}$ species at the surface of alumina being only very weakly acidic (spectra not shown). The band at $1613 \mathrm{~cm}^{-1}$ is due to ammonia molecules coordinated by $\mathrm{V}^{5+}$ Lewis acidic sites. Ammonia dosage on V50Al sample outgassed at $300^{\circ} \mathrm{C}$ (Section $b$ ), gave rise to the formation of similar bands, but that of ammonium ions $\left(1426 \mathrm{~cm}^{-1}\right)$ was much less intense, due to surface dehydroxylation and consequent disappearance of the $\mathrm{V}-\mathrm{OH}$ species. In both cases, adsorption of ammonia was not fully reversible after prolonged evacuation at room temperature (bold lines in Fig.s $7 a$ and $b$ ), indicating the presence of rather strong Brønsted and Lewis sites. 
Fig.8 compares the normalised difference spectra obtained after dosage of ammonia on samples V10Al and V10Al-i. In both cases ammonia coordinates to Lewis acidic sites (bands at ca. $1610 \mathrm{~cm}^{-1}$ ) and to Brønsted sites, forming ammonium ions. With the FP-prepared sample (Section a), however, the observed frequency for ammonium band $\left(1422 \mathrm{~cm}^{-1}\right)$ is lower than with the impregnated sample $\left(1430 \mathrm{~cm}^{-1}\right)$, showing that interaction with ammonia is stronger, i.e. Brønsted sites at the surface of V10Al are stronger than those at the surface of VAl10-i. This result is also confirmed by the partial reversibility of the band due to ammonium ions with sample V10Al-i after prolonged evacuation at r.t. (bold lines), whereas no change is observed after ammonia evacuation at r.t. from sample V10Al.

\section{4 - Nature of active sites}

A different nature and structure of the active sites appears when comparing samples prepared by FP and impregnation. Much higher V dispersion through the bulk is achieved with the former than with the latter, which shows only surface coverage by $\mathrm{V}$ species. However, lower dispersion has been observed with the present FP-prepared VAl-O samples than with the V-Si-O ones [11]. Indeed, some segregated vanadia was here observed even at $10 \% \mathrm{~V}$ loading and some interaction between $\mathrm{V}^{4+}$ species has been shown also by the aged V10Al catalyst. The increase of V loading increases the amount of segregated $\mathrm{V}_{2} \mathrm{O}_{5}$, as clearly evidenced by $\mathrm{XRD}$, Raman and EPR (i.e. EPR or FMR). However, the Raman spectra of V10Al-i seems more similar to V50Al than to V10Al, which shows also the presence of some isolated $\mathrm{V}=\mathrm{O}$ species, confirming the low $\mathrm{V}$ dispersion obtained by impregnation.

The actual form of the active site can be hypothesised by considering the EPR pattern, though referring to $\mathrm{V}^{4+}$ species. Spectra simulation led to a planar configuration of $\mathrm{VO}_{\mathrm{x}}$ with a $\mathrm{V}=\mathrm{O}$ bond perpendicular to it. 


\section{5- Catalytic activity: redox tests}

The catalytic activity of all samples was compared both by simultaneously feeding propane and oxygen (co-feeding mode) and under anaerobic conditions, corresponding to the first step of the cyclic redox-decoupling mode, in which the feed of the hydrocarbon alternates with that of oxygen. The latter procedure allows alternate reaction and regeneration steps, so avoiding the co-presence of propane and oxygen. The catalytic behaviour has been then compared with that of the impregnated sample.

Fig.9 summarizes the catalytic performance under anaerobic conditions, i.e., in the presence of the propane/He only, both at 500 and $550^{\circ} \mathrm{C}$. The higher the $\mathrm{V}$ content, the higher was the initial (i.e., after 1 min on-stream, when the catalyst was still fully oxidised) propane conversion (Fig.9a). The progressive reduction of catalyst immediately led to a decline of activity. After approx 10 min on-stream, the activity stabilized but after 20 min the catalysts still showed a very slow decline of activity (this phenomenon was more evident with the $\mathrm{V} 50 \mathrm{Al}$ catalyst, at $550^{\circ} \mathrm{C}$ ), indicating a progressive catalyst deactivation, likely due to coke accumulation. The final dehydrogenation activity at $550^{\circ} \mathrm{C}$, after $30 \mathrm{~min}$ on-stream, was proportional to the V content, with the only exception of the V50Al catalyst, which showed the lowest propane conversion. On the contrary, at $500^{\circ} \mathrm{C}$ the final conversion was the same for all samples.

Fig. $9 \mathrm{~b}$ plots the change of selectivity to propylene as a function of propane conversion, at $550^{\circ} \mathrm{C}$; it is worth reminding that the higher propane conversion was obtained, for each catalyst, at the beginning of the reactivity test, when the sample was still oxidized. The decrease of conversion caused an improvement of selectivity to propylene, due both to the lower consecutive propylene combustion and to an increasing contribution of propane dehydrogenation versus oxidative dehydrogenation on the more reduced catalyst [45-48]. 
Fig.10 plots the change of selectivity to each product as a function of time-onstream under anaerobic conditions, for catalyst $\mathrm{V} 10 \mathrm{Al}$, at $550^{\circ} \mathrm{C}$. The increase of selectivity to propylene was concomitant to the decrease of $\mathrm{CO}_{2}$ formation. The concentration of $\mathrm{H}_{2}$, initially nil for the fully oxidized catalyst, increased along with the increasing reduction degree of vanadium oxide. The final concentration of $\mathrm{H}_{2}(2.5 \mathrm{~mol} \%)$, however, was slightly higher than that one of propylene (1.7 mol\%), because the formation of coke also contributed to hydrogen formation. The $\mathrm{C}$ balance after 15 min on-stream was $92-93 \%$, confirming that some coke accumulated on the catalyst surface. In general, however, the selectivity to coke (calculated from the lack in the C-balance) with all catalysts was never higher than $10-15 \%$, lower than that observed with the V-Si-O catalysts [11]. It is worth to mention that the decline of selectivity to $\mathrm{CO}_{2}$ was more rapid than that to $\mathrm{CO}$; this may be due to the reaction: $\mathrm{C}+\mathrm{CO}_{2} \rightarrow 2 \mathrm{CO}$, that may also explain the low amount of coke formed on these catalysts.

Fig.10 also shows that the higher the initial propane conversion was (for the fully oxidized catalyst), the lower was the selectivity to propylene. However, the latter was not simply a function of propane conversion, but also of the amount of vanadium oxide; in fact, the higher the amount of $\mathrm{V}_{2} \mathrm{O}_{5}$, the higher was the selectivity to propylene for a given level of propane conversion. This was due to the fact that selectivity to propylene under anaerobic conditions was due to the contribution of two concomitant factors, firstly the degree of propane conversion and secondly the relative contribution of $\mathrm{ODH} v \mathrm{vH}$, the latter being a function of the reduction level of vanadium oxide.

Fig.11 reports the conversion of propane for repeated reaction cycles, for V10Al and V25Al catalysts, each cycle being preceded by a re-oxidizing step, done in flowing air for $30 \mathrm{~min}$ at $550^{\circ} \mathrm{C}$, that is the maximum reaction temperature used in propane $\mathrm{ODH}$ tests. Indeed, preliminary tests showed that 30 minutes on-stream were sufficient to attain the maximum level of vanadium re-oxidation. For both catalysts the first cycle gave higher 
initial propane conversion than the second cycle; the final activity, for the reduced sample after prolonged operation in the absence of oxygen, was the same for all reaction cycles. In the case of the V25Al catalyst, a third cycle was carried out, that gave the identical trend of propane conversion as for the second cycle. These data indicate that the reduction of the fresh samples during the first reaction step led to a modification of the active phase properties. Reduction of $\mathrm{V}^{5+}$ leading to the formation of species not reoxidizable at $550^{\circ} \mathrm{C}$ could also be possible.

\section{5 - Catalytic activity: co-feed tests}

Fig.12 compares the conversion of propane (a) and the selectivity to propylene (b) for the four catalysts investigated, under co-feed (aerobic) conditions. The activity was proportional to the $\mathrm{V}$ oxide loading. Sample V50Al led to total conversion of oxygen, the limiting reactant, at $320^{\circ} \mathrm{C}$, the maximum propane conversion being $29 \%$. The least active catalyst was V10Al; in this case total oxygen conversion was obtained at $400^{\circ} \mathrm{C}$. For all catalysts, however, a further increase of temperature led to an increase of propane conversion. This was due to the additional contribution of propane $\mathrm{DH}$ that overlapped to oxidative transformations. For all catalysts the selectivity to propylene was higher than $40 \%$ when the conversion of propane was $2-3 \%$, but then rapidly decreased down to a minimum value when temperature was increased. The selectivity to propylene at total oxygen conversion was $19 \%$ for $\mathrm{V} 10 \mathrm{Al}, 14 \%$ for $\mathrm{V} 25 \mathrm{Al}$ and $10 \%$ for samples possessing the highest amount of $\mathrm{V}$ oxide, i.e. $\mathrm{V} 50 \mathrm{Al}$ and $\mathrm{AlVO}_{4}$. Then, the selectivity to propylene increased again at high temperature, because of propane $\mathrm{DH}$; at $530^{\circ} \mathrm{C}$ all catalysts gave approx. 25\% selectivity to propylene, regardless the $\mathrm{V}$ oxide content. Under these conditions, there was a significant formation of $\mathrm{H}_{2}$; its outlet concentration was 1.4-1.6 mol\% at $530^{\circ} \mathrm{C}$, that corresponds to the concentration of propylene produced. The $\mathrm{C}$ balance was close to $100 \%$, and hence there was negligible formation of coke; therefore, 
at $530^{\circ} \mathrm{C}$ propylene was mainly produced by $\mathrm{DH}$. Another aspect was the non-negligible production of acetic acid at low temperature, i.e. under incomplete conversion of oxygen; the maximum selectivity was less than $5 \%$ for catalysts $\mathrm{V} 10 \mathrm{Al}$ and $\mathrm{V} 25 \mathrm{Al}$, but ca. $10 \%$ at $300^{\circ} \mathrm{C}$ for catalyst $\mathrm{AlVO}_{4}$.

Catalysts did not show relevant deactivation phenomena during catalytic tests, at least within the 20-30 hours necessary to complete the reactivity measurements. However, when the reaction temperature was kept for more than $1-2 \mathrm{~h}$ above that at which total oxygen conversion was reached, the catalyst showed some deactivation effect. This was found to be due to the accumulation of coke.

\section{6 - Comparison between FP and impregnated catalysts}

Fig.13 compares the catalytic performance under redox conditions for catalysts V10Al and V10Al-i. The two samples showed quite similar propane conversion, whereas the selectivity to propylene was slightly higher for the catalyst prepared by FP. The two samples also had similar behaviour under co-feed conditions, both in terms of activity and selectivity to propylene.

In our previous work [11], we found that the $\mathrm{V} / \mathrm{Si} / \mathrm{O}$ catalyst containing $10 \mathrm{wt} \% \mathrm{~V}_{2} \mathrm{O}_{5}$ and prepared with the FP method was remarkably more selective to propylene under anaerobic conditions than the corresponding sample prepared by impregnation of FPprepared silica, especially for the fully oxidized catalysts (i.e. at very low time-on-stream). This was attributed to the generation of peculiar species in FP-prepared V/Si/O catalysts. It was found that a much higher dispersion of active sites could be achieved with respect to samples prepared by conventional techniques. In fact, the initial embedment of the $\mathrm{V}$ species into the support matrix, occurring during the pyrolysis, and the successive hydrolysis of strained Si-O-Si and Si-O-V bonds, led to the exposure of subsurface $\mathrm{V}$ sites and to the formation of a greater fraction of isolated $V$ sites. By contrast, in the case of the 
present V-Al-O catalysts, the IR characterization did not indicate the presence of an anomalous concentration of surface hydroxyl groups. This indicates that the same phenomena that are responsible for the generation of a high concentration of isolated $\mathrm{V}$ species in V-Si-O catalysts do not occur with the V-Al-O systems anymore. This also is in agreement with the well-known hydrolizability of surface $\mathrm{V}-\mathrm{O}-\mathrm{Si}$ bonds in silica-supported vanadium oxide catalysts, as compared to the analogous alumina-supported systems.

Therefore, in the case of the V-Al-O catalysts, the FP method does not yield a better dispersion of the $\mathrm{V}$ sites as compared to the impregnation method. Another role is likely played by the mechanism of particle formation during the FP synthesis. In the case of single oxides, a correlation between the rates of solvent evaporation/ion diffusion and the formation of hollow particles was demonstrated [19,49]. For multicomponent systems an additional segregation phenomenon can also occur $[24,50]$. For instance, in the present case poor $\mathrm{V}$ incorporation into the alumina matrix was observed even at low $\mathrm{V}$ loading, leading to a catalyst that is not so different from that prepared by impregnation. By contrast, when carboxylic acids + organic precursor are used for the preparation of the silica based samples, a better incorporation of the active phase into the support was achieved, leading to isolated vanadyl species even at high $\mathrm{V}$ loading and ensuring a selectivity gain under anaerobic conditions with respect to the sample prepared by impregnation. Here, however, a better solvent/precursor selection was precluded (vide supra) by solubility problems for the precursors.

\section{7- Comparison between redox an co-feed operation for FP catalysts}

Fig. 14 compares the selectivity to propylene as a function of propane conversion for the catalysts prepared with the FP method, for co-feed and anaerobic operations. It is evident that for propane conversion in the $10-20 \%$ range, the selectivity to propylene achieved under anaerobic conditions was 30-40 points \% higher than that obtained under 
co-feed conditions. The catalytic performance under anaerobic conditions shown in the Figure is identical to that obtained with $\mathrm{V}$-Al-O catalysts prepared by conventional impregnation of a high-surface-area alumina [45]. In that case, however, the gain in selectivity achieved with the anaerobic operation, with respect to the co-feed, was not higher than $20 \%$. This is due to the fact that under co-feed conditions the impregnated samples gave a better selectivity to propylene than the present $\mathrm{V}$-Al-O catalysts, especially for catalysts having a lower $\mathrm{V}$ content, likely because of the higher surface area of that alumina support and hence of the better dispersion of vanadium oxide.

EPR characterization provided information on the strength of the $V=O$ bond in our samples. The bond is apparently weaker with the V-Al-O than with the V-Si-O catalysts, both having been prepared by the FP method. Stronger $\mathrm{V}=\mathrm{O}$ bonds led to higher selectivity in methanol oxidation to formaldehyde [27] but to lower catalytic conversion in methane oxidation [39]. Therefore, in the present case a higher conversion is expected with the $\mathrm{V}-\mathrm{Al}-\mathrm{O}$ than with the $\mathrm{V}-\mathrm{Si}-\mathrm{O}$ samples, though the latter would lead to a higher selectivity, especially under anaerobic conditions. Indeed, this has been observed in the present investigation. Even though the surface area of $\mathrm{V}-\mathrm{Al}-\mathrm{O}$ is much lower than that of V-Si-O catalysts [11], the catalytic activity of the former samples is higher, under both cofeed and anaerobic conditions. However, the selectivity evaluated at the same conversion level is clearly higher for the V-Si-O catalysts.

In summary, these data indicate that the different catalytic performance of the two modes of operation is governed mainly by the nature and strength of the $\mathrm{V}=\mathrm{O}$ bond. However, with V-Al-O catalysts, the degree of $\mathrm{V}$ oxide dispersion affects to a greater extent the selectivity to propylene when the reaction is carried out in the presence of molecular oxygen. The degree of $\mathrm{V}$ dispersion is affected not only by the amount of vanadium oxide loading, but also by the method of preparation. 


\section{4- Conclusions}

A set of $\mathrm{V} / \mathrm{Al} / \mathrm{O}$ catalysts have been prepared by FP and tested for the ODH of propane. The samples showed a relatively low surface area and morphological homogeneity with respect to other FP-prepared materials, such as V/Si/O [11]. This can be ascribed to FP solvent and precursor nature, imposed by the Al precursor solubility. However, the particle size became progressively more uniform with increasing $\mathrm{V}$ loading, due to the positive action of $\mathrm{V}$ ions during precursors and solvent oxidation. Indeed, due to the mechanism of particle formation in the case of alcohol-based solvents, $\mathrm{V}$ incorporation into the alumina matrix was not completely achieved, leading to some $\mathrm{V}_{2} \mathrm{O}_{5}$ segregation even at low $\mathrm{V}$ loading. However, higher $\mathrm{V}$ dispersion was attained with respect to a reference sample prepared by impregnation.

Catalytic activity was tested under anaerobic conditions and by co-feeding propane + under-stoichiometric oxygen. In every case, an increase of $\mathrm{V}$ loading brought about an increase of propane conversion. However, selectivity at the same conversion level increased with $\mathrm{V}$ concentration during operation under anaerobic conditions, whereas the opposite trend was observed in the co-feeding mode.

The comparison with the reference sample prepared by impregnation of the FPprepared alumina showed similar performance. The selectivity improvement observed with $\mathrm{V} / \mathrm{Si} / \mathrm{O}$ catalysts [11] is much lower with the present $\mathrm{V} / \mathrm{Al} / \mathrm{O}$ catalysts, due to lower $\mathrm{V}$ dispersion in the latter samples.

\section{ACKNOWLEDGEMENTS}

MUR (Italian Ministry of University and Research) is gratefully acknowledged for financial support through the PRIN2005 (2005 038244) programme. INSTM is gratefully acknowledged for a PhD grant to A. Cericola. The Nowegian Research Council is 
gratefully acknowledged for the PhD grant and travel grant for Hilde Dyrbeck through the KOSK programme. We are also grateful to Dr. S. Cappelli for EPR spectra collection.

\section{REFERENCES}

1. N. Ballarini, F. Cavani, A. Cericola, Catal. Today 127 (2007) 113.

2. M.D. Argyle, K. Chen, A.T. Bell, E. Iglesia, J. Catal. 208 (2002) 139.

3. T. Blasco, A. Galli, J. M. Lòpez Nieto, F. Trifirò, J. Catal. 169 (1997) 203.

4. Z. Zhao, Y. Yamada, A. Ueda, H. Sakurai, T. Kobayashi, Catal. Today 93-95 (2004) 163.

5. M.V. Martìnez-Huerta, X. Gao, H. Tian, I.E. Wachs, J.L.G. Fierro, M.A. Bañares, Catal. Today 118 (2006) 279.

6. E.V. Kondratenko, N. Steinfeldt, M. Baerns, Phys. Chem. Chem. Phys. 8 (2006) 1624.

7. D. Shee, T.V. Malleswara Rao, G. Deo, Catal. Today 118 (2006) 288.

8. H. Tian, E.I. Ross, I.E. Wachs, J. Phys. Chem. B 110 (19) (2006) 9593.

9. K. Chen, E. Iglesia, A.T. Bell, J. Catal. 192 (2000) 197.

10. S. Dz'wigaj, I. Gressel, B. Grzybowska, K. Samson, Catal. Today 114 (2006) 237.

11.I. Rossetti, L. Fabbrini, N. Ballarini, C. Oliva, F. Cavani, A. Cericola, B. Bonelli, M. Piumetti, E. Garrone, H. Dyrbeck, E.A. Blekkan, L. Forni, J. Catal.,256 (2008) 45.

12. M.D. Argyle, K. Chen, C. Resini, C. Krebs, A.T. Bell, E. Iglesia, J. Phys. Chem. B 108 (2004) 2345.

13. N. Steinfeldt, D. Müller, H. Berndt, Appl. Catal., A 272 (2004) 201.

14.W.J. Stark, L. Mädler, S.E. Pratsinis, EP 1,378,489 A1 (2004), to ETH, Zurich.

15. G.L. Chiarello, I. Rossetti, L. Forni, J. Catal. 236 (2005) 251.

16. G.L. Chiarello, I. Rossetti, P. Lopinto, G. Migliavacca, L. Forni, Catal. Today 117 (2006) 549. 
17. G.L. Chiarello, I. Rossetti, L. Forni, P. Lopinto, G. Migliavacca, Appl. Catal., B 72 (2007) 218.

18. G.L. Chiarello, I. Rossetti, L. Forni, P. Lopinto, G. Migliavacca, Appl. Catal., B 72 (2007) 227.

19. L. Mädler, S.E. Pratsinis, J. Am. Ceram. Soc. 85 (7) (2002) 1713.

20. R. Strobel, S.E. Pratsinis, A. Baiker, J. Mater. Chem. 15 (2005) 605.

21. R. Strobel, W.J. Stark, L. Mädler, S.E. Pratsinis, A. Baiker, J. Catal. 213 (2003) 296.

22. R. A. M. Giacomuzzi, M. Portinari, I. Rossetti, L. Forni, Stud. Surf. Sci. Catal., A. Corma, F.V. Melo, S. Mendioroz, J.L.G. Fierro Eds., Vol. 130, Elsevier, Amsterdam, (2000) 197.

23. Advanced Selected Powder Diffraction Data, Miner. DBM (1-40), J.C.P.D.S., Swarthmore, PA, 1974-1992.

24.W.J. Stark, L. Mädler, M. Maciejewski, S.E. Pratsinis, A. Baiker, Chem. Comm. (2003) 588

25. R. Tohmon, Y. Shimogaichi, Y. Tsuta, S. Munekuni, Y. Ohki, Y. Hama, K. Nagasawa, Phys. Rev. B 41 (1990) 7258.

26.K. Chah, B. Boizot, B. Reynard, D. Ghaleb, G. Petite, Nuclear Instrum. and Methods in Phys. Research B 191 (2002) 337.

27. V.K. Sharma, A. Wokaun, A. Baiker, J. Phys. Chem. 90 (1986) 2715.

28. T. Demiray, D.K. Nath, F.A. Hummel, J. Am. Ceram. Soc. 53 (1970) 1.

29. A. Beltrán, S. Bohm, A. Flore-Riveros, J.A. Igualada, G. Monros, J. Andrés, V. Luaña, A. Martín Pendás, J. Phys. Chem. 97 (1993) 2555.

30.S. Di Gregorio, M. Greenblatt, J.H. Pifer, M.D. Sturge, J. Chem. Phys. 76 (1982) 2931.

31.D. de Waal, A.M. Heyns, G. Pretorius, R.J.H. Clark, J. Raman Spectr. 27 (1996) 657. 
32. H. Xiayou, B. Gui-Ku, Z. Min-Guang, J. Phys. Chem. Solids 46 (1985) 719.

33.P. Chandley, R.J.H. Clark, R.J. Angel, G.D. Price, J. Chem. Soc. Dalton Trans.. 9 (1992) 1579.

34.M. Ocana, A.R. Gonzalez-Elipe, V.M. Orera, P. Tartaj, C.J. Serna, R.I. Merino, J. Am. Ceram. Soc. 81 (1998) 395.

35. A. Siggel, M. Jansen, Z. Anorg. Allg. Chem. 583 (1990) 67.

36. A. Niesert, M. Hanrath, A. Siggel, M. Jansen, K. Langer, J. Solid State Chem.. 169 (2002) 6 .

37. S. Ardizzone, G. Cappelletti, P. Fermo, C. Oliva, M. Scavini, F. Scimé, J. Phys. Chem. B 109 (2005) 22112.

38. K.V.R. Chary, B. Mahipal Reddy, N.K. Nag, V.S. Subrahmanyam, J. Phys. Chem. 88 (1984) 2622.

39. A. Gervasini, G. Fornasari, G. Bellussi, Appl. Catal., A 83 (1992) 235.

40.J.E. Wertz, J.R. Bolton, "Electron Spin Resonance. Theory and Applications", McGraw-Hill, New York, 1972, 288.

41.M.V. Martinez-Huerta, X. Gao, H. Tian, I.E. Wachs, J.L.G. Fierro, M.A. Banares, Catal. Today 118 (2006) 279.

42. N. Magg, B. Immaraporn, J.B. Giorni, J. Catal. 226 (2004) 88.

43. C. Morterra, G. Magnacca, Catal. Today 27 (1996) 497.

44. J.A. Lercher, C. Gründling, G. Eder-Mirth, Catal. Today 27 (1996) 353.

45. N. Ballarini, A. Battisti, F. Cavani, A. Cericola, C. Lucarelli, S. Racioppi, P. Arpentinier, Catal. Today 116 (2006) 313.

46. N. Ballarini, F. Cavani, A. Cericola, C. Cortelli, M. Ferrari, F. Trifirò, R. Catani, U. Cornaro, Stud. Surf. Sci. Catal. Natural Gas Conversion VII, Proceedings of the $7^{\text {th }}$ Natural Gas Conversion Symposium, X. Bao and Y. Xu Eds., Vol. 147 Elsevier, Amsterdam (2004) 649. 
47. N. Ballarini, F. Cavani, M. Ferrari, R. Catani, U. Cornaro, J. Catal. 213 (2003) 95.

48. N. Ballarini, A. Battisti, F. Cavani, A. Cericola, C. Cortelli, M. Ferrari, F. Trifirò, P. Arpentinier, Appl. Catal., A 307 (2006) 148.

49. R. Jossen, W.J. Stark, L. Mädler, S.E. Pratsinis, Chem. Ing. Tech. 75 (2003) 1129.

50. M.C. Heine, S.E. Pratsinis, Ind. Eng. Chem. Res. 44 (2005) 6222. 


\section{TABLES}

Table 1: Catalyst composition and specific surface area (SSA).

\begin{tabular}{|c|c|c|c|}
\hline Sample & $\begin{array}{c}\text { \% wt V/V+Al } \\
\text { exp. }\end{array}$ & $\begin{array}{c}\text { \% wt V/V+Al } \\
\text { nominal }\end{array}$ & SSA $\left(\mathrm{m}^{2} / \mathrm{g}\right)$ \\
\hline $\mathrm{Al}_{2} \mathrm{O}_{3}$ & $/$ & $/$ & 20 \\
\hline $\mathrm{Al}_{2} \mathrm{O}_{3}\left(600^{\circ} \mathrm{C}\right)$ & $/$ & $/$ & 18 \\
\hline $\mathrm{V} 10 \mathrm{Al}$ & 11.2 & 9.6 & 19 \\
\hline $\mathrm{V} 25 \mathrm{Al}$ & 23.9 & 20.9 & 23 \\
\hline $\mathrm{V} 50 \mathrm{Al}$ & 38.4 & 34.6 & 21 \\
\hline $\mathrm{AlVO} 4$ & 69.9 & 65.4 & 20 \\
\hline $\mathrm{V} 10 \mathrm{Al}-\mathrm{i}$ & n.d. & 9.6 & 27 \\
\hline
\end{tabular}

* Determined by ICP-MS

Table 2: Weight loss during TGA analysis and temperature of the main peaks observed.

\begin{tabular}{|c|c|cc|c|}
\hline Sample & 1st peak T $\left({ }^{\circ} \mathbf{C}\right)$ & 2nd peak T $\left({ }^{\circ} \mathbf{C}\right)$ Total \% wt loss & 2nd peak \% wt loss \\
\hline V10Al & - & 680 & 4.1 & 0.6 \\
\hline V25Al & - & 665 & 4.7 & 0.5 \\
\hline V50Al & 100 & 395 & 4.2 & 0.6 \\
\hline AlVO $_{4}$ & 65 & 400 & 8.3 & 0.4 \\
\hline
\end{tabular}


Table 3: EPR experimental parameters

\begin{tabular}{|l|c|c|c|c|c|c|c|}
\hline sample & $\mathbf{g}_{/ /}$ & $\boldsymbol{g}_{\perp}$ & $\begin{array}{c}\boldsymbol{B} \\
\left(^{*}\right)\end{array}$ & $\boldsymbol{A}_{/ /} / \mathbf{G}$ & $\boldsymbol{A}_{\perp} / \mathbf{G}$ & $\begin{array}{c}\Delta \boldsymbol{W}_{/ /} / \mathbf{G} \\
\left({ }^{\circ}\right)\end{array}$ & $\begin{array}{c}\Delta \boldsymbol{W}_{\perp} / \mathbf{G} \\
\left({ }^{\circ}\right)\end{array}$ \\
\hline $\begin{array}{l}\mathbf{1 0} \mathbf{\%}_{\mathbf{2}} \mathbf{O}_{\mathbf{5}} \\
\text { on } \mathbf{A l}_{\mathbf{2}} \mathbf{O}_{\mathbf{3}}\end{array}$ & 1.940 & 1.960 & 1.47 & 180 & 80 & 60 & 60 \\
\hline $\begin{array}{l}\mathbf{1 0 - 5 0 \%} \\
\mathbf{V}_{\mathbf{2}} \mathbf{O}_{5} \text { on } \\
\mathbf{S i O}_{\mathbf{2}} \mathbf{( \$ )}\end{array}$ & 1.940 & 1.985 & 3.60 & 194 & 77 & 20 & 15 \\
\hline
\end{tabular}
(*) from eq.(1) of the text
$\left({ }^{\circ}\right)$ Lorentzian-shaped line widths
(\$) data from ref. [11] 


\section{FIGURE CAPTIONS}

Fig.1: XRD patterns of the prepared samples a) Bare alumina and alumina-supported V samples, b) $\mathrm{AlVO}_{4}$ samples, as prepared and calcined. $\bullet=\mathrm{V}_{2} \mathrm{O}_{5}$ (file 009-0387); $\square=\delta$ - or $\eta-\mathrm{Al}_{2} \mathrm{O}_{3}$ (files 046-1131 and 004-0875); $\mathrm{x}=\mathrm{AlVO}_{4}$ (file 039-0276) [23].

Fig.2: SEM micrographs of the prepared samples. Marker size: $500 \mathrm{~nm}$ except for $\mathrm{AlVO}_{4}$ $(1 \mu \mathrm{m})$.

Fig.3: EPR spectra of samples V10AI (a) and V10Al-i (b). Inset: EPR spectrum at room temperature of sample V10Al: top, experimental; bottom, simulation. An arrow indicates the $9 \mathrm{G}$ narrow line due to $\mathrm{E}^{\prime}$ defects present in $\mathrm{Al}_{2} \mathrm{O}_{3}$.

Fig.4: EPR spectra at room temperature of sample V25Al (a) as prepared and (b) after reaction in co-feed mode. FMR1 and FMR2 indicate ferromagnetic resonance features due to $\mathrm{V}^{4+}$-based clusters (see text).

Fig.5: EPR spectra of a) $\mathrm{AlVO}_{4}$ sample; b) sample V50Al after reaction under anaerobic conditions. Top: experimental; bottom: simulation.

Fig.6: FT-IR spectra in the hydroxyls range $\left(3800-3200 \mathrm{~cm}^{-1}\right)$ of samples outgassed at $150^{\circ} \mathrm{C}$. Curves $\mathrm{a}, \mathrm{b}$ and $\mathrm{c}$ refer to samples $\mathrm{Al}_{2} \mathrm{O}_{3} ; \mathrm{V} 10 \mathrm{Al}$; V50Al, respectively; in the inset, V10Al-i spectrum is reported.

Fig.7: Difference spectra, in the $1800-1150 \mathrm{~cm}^{-1}$ range, recorded after dosing $\mathrm{NH}_{3}$ on sample V50Al outgassed at 150 (Section a) and $300^{\circ} \mathrm{C}$ (Section $b$ ). Equilibrium pressures 
on $\mathrm{NH}_{3}$ in the $0.01-23.0$ mbar range; bold curves: spectra recorded after prolonged evacuation (30 $\mathrm{min})$ at room temperature.

Fig.8: Difference spectra, in the $1800-1150 \mathrm{~cm}^{-1}$ range, recorded after dosing $\mathrm{NH}_{3}$ on samples V10Al (Section a) and V10Al-i (Section b) outgassed at $150^{\circ} \mathrm{C}$. Equilibrium pressures on $\mathrm{NH}_{3}$ in the $0.01-23.0$ mbar range; bold curves: spectra recorded after prolonged evacuation (30 $\mathrm{min}$ ) at room temperature.

Fig.9: Conversion of propane as a function of time-on-stream (a) and selectivity to propylene as a function of propane conversion (b), under anaerobic conditions at $500^{\circ} \mathrm{C}$ $\left(450^{\circ} \mathrm{C}\right.$ for catalyst $\mathrm{AlVO}_{4}$,) (open symbols) and $550^{\circ} \mathrm{C}$ (full symbols). Catalysts: V10Al $(\bigcirc), \operatorname{V25Al}(\square \mathbf{\square}), \operatorname{V50Al}(\triangle \boldsymbol{\Delta})$ and $\mathrm{AlVO}_{4}(\diamond \diamond)$

Fig.10: Selectivity to propylene $(\bullet), \mathrm{CO}_{2}(\mathbf{\Delta}), \mathrm{CO}(\boldsymbol{\square})$, light hydrocarbons $(\boldsymbol{O})$, and concentration of $\mathrm{H}_{2}$ at in the outlet stream ( $\square$ ) as functions of time-on-stream under anaerobic conditions, at $550^{\circ} \mathrm{C}$. Catalyst V10Al.

Fig.11: Conversion of propane as a function of time-on-stream under anaerobic conditions for the V10Al catalyst (triangles), and the V25Al catalyst (diamonds). First cycle (black symbols), second cycle (grey symbols), third cycle (white symbols).

Fig.12: Conversion of propane (a) and selectivity to propylene (b) as a function of temperature under co-feed conditions. Symbols as in Fig 9. 
Fig.13: Conversion of propane (triangles) and selectivity to propylene (squares) as a function of time-on-stream under anaerobic conditions, for catalysts V10Al (open symbols) and V10Al-i (full symbols).

Fig.14: Selectivity to propylene as a function of propane conversion for anaerobic operation (full symbols) and for co-feed operation (open symbols). Catalysts: symbols as in Fig.9. 
Fig.1a

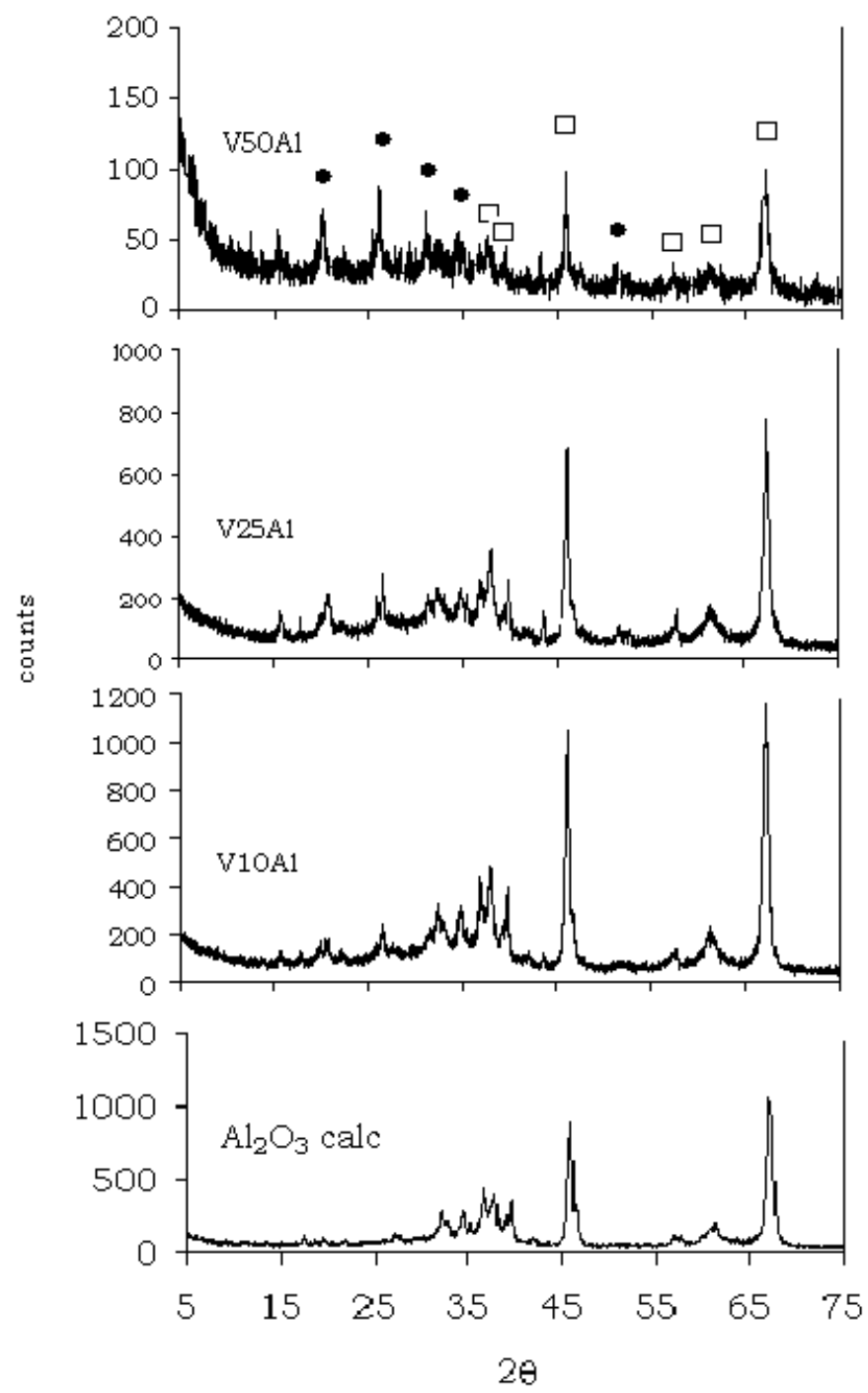


Fig. 1b

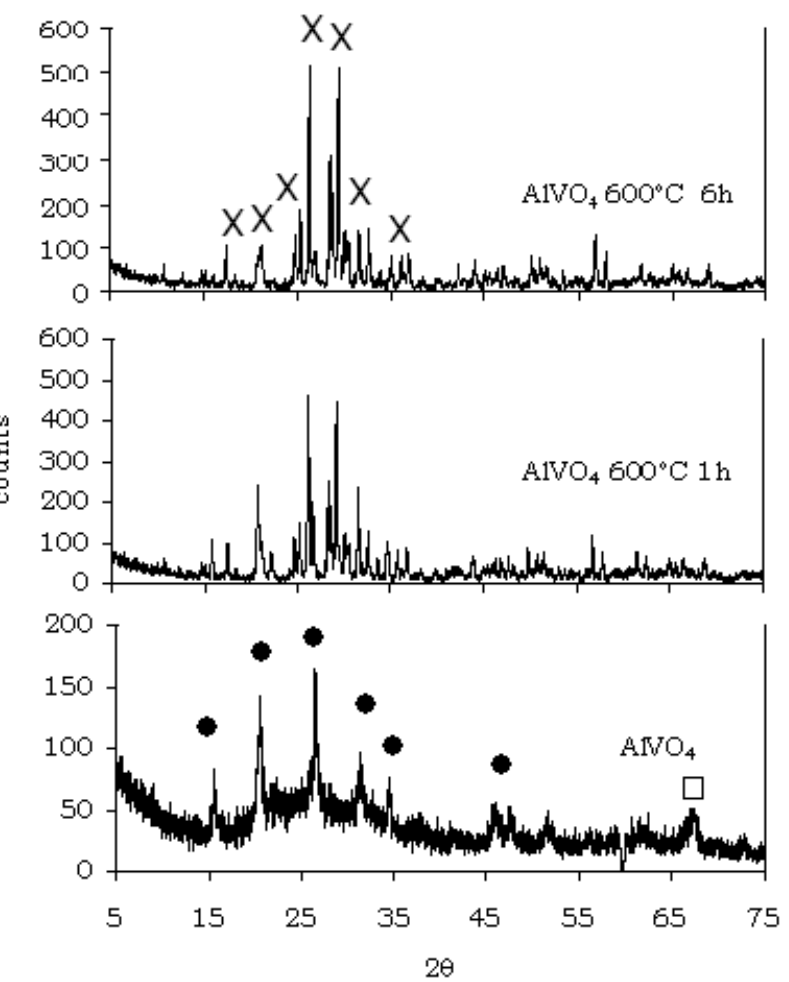


Fig.2

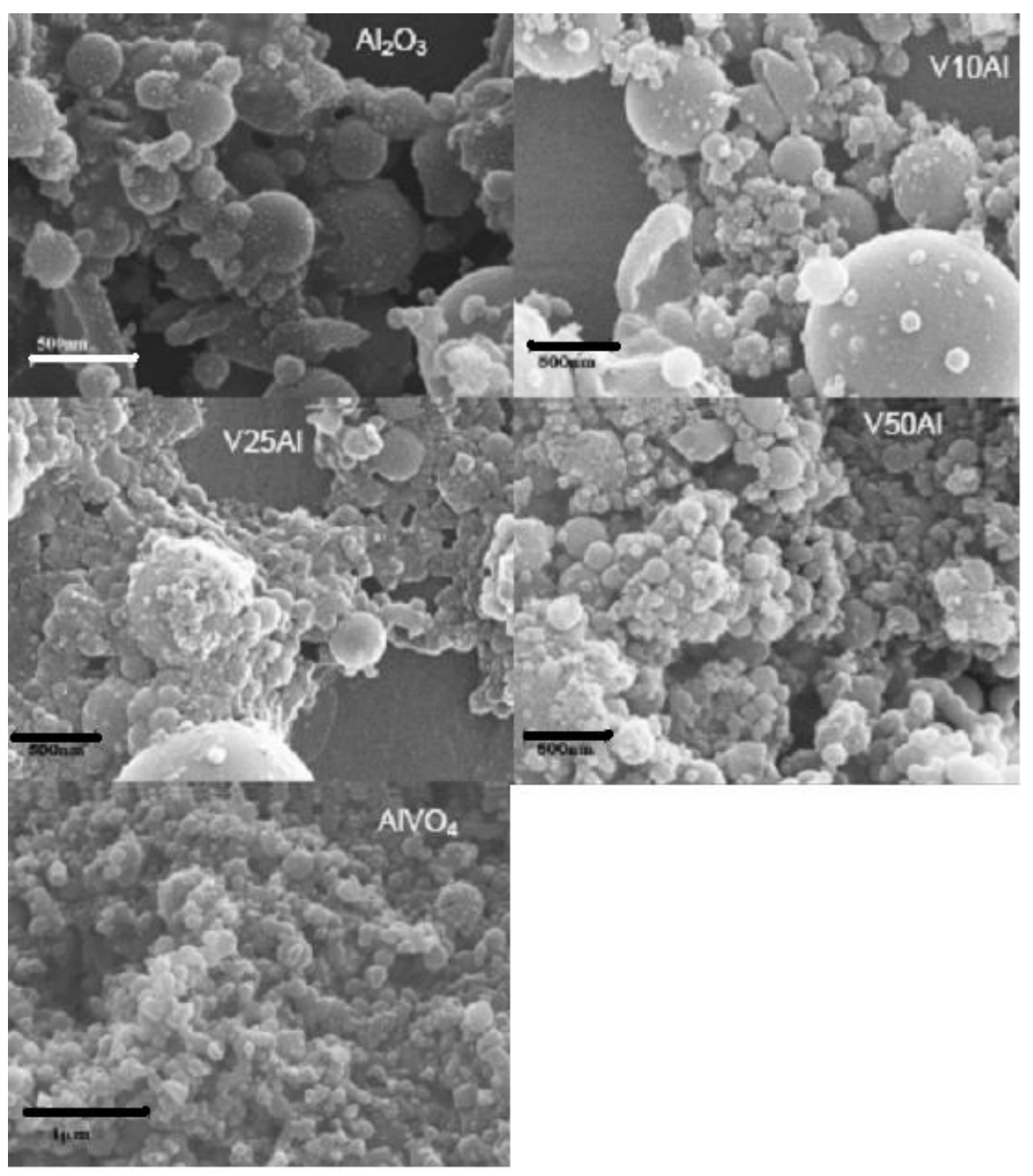


Fig.3.

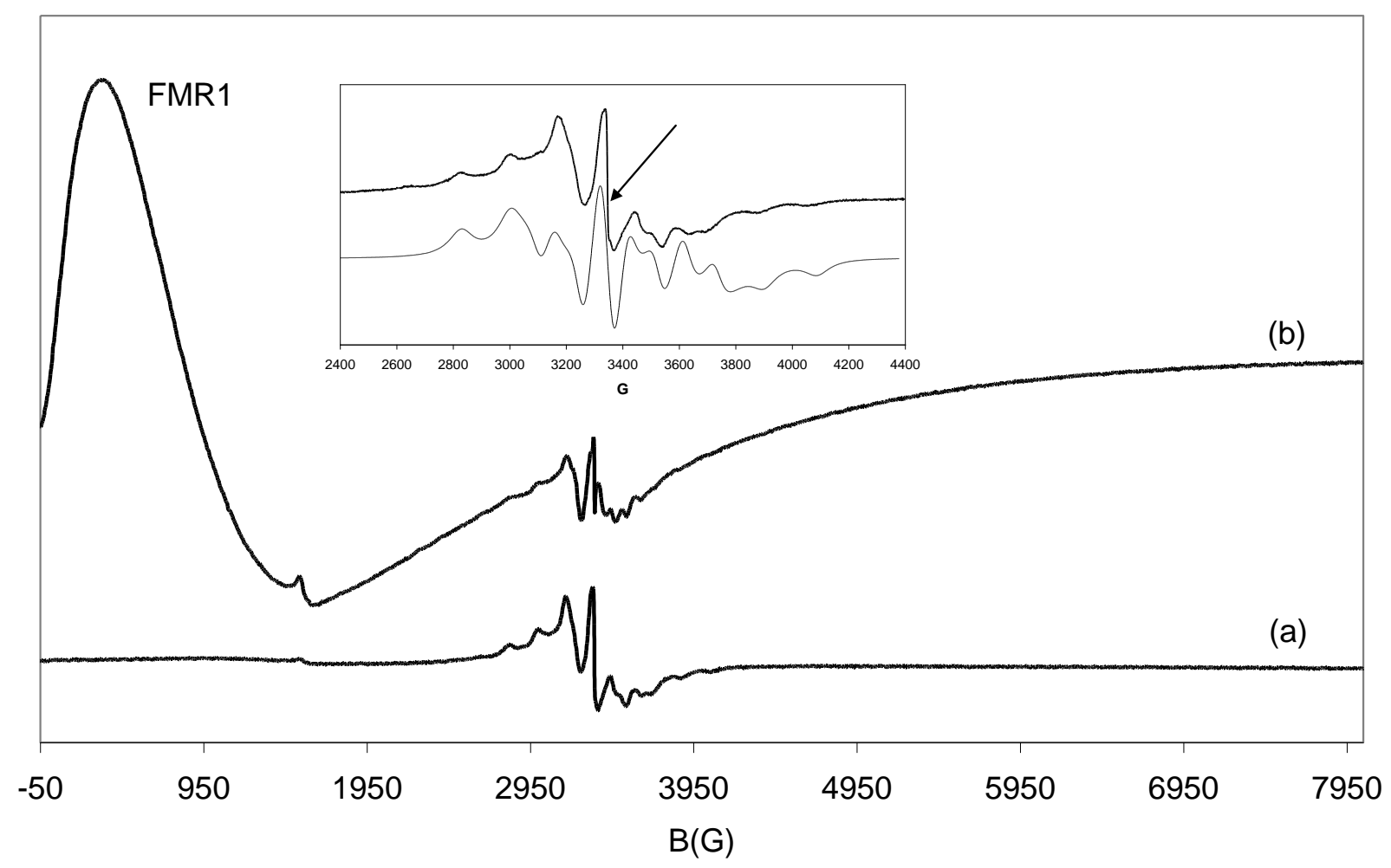


Fig.4

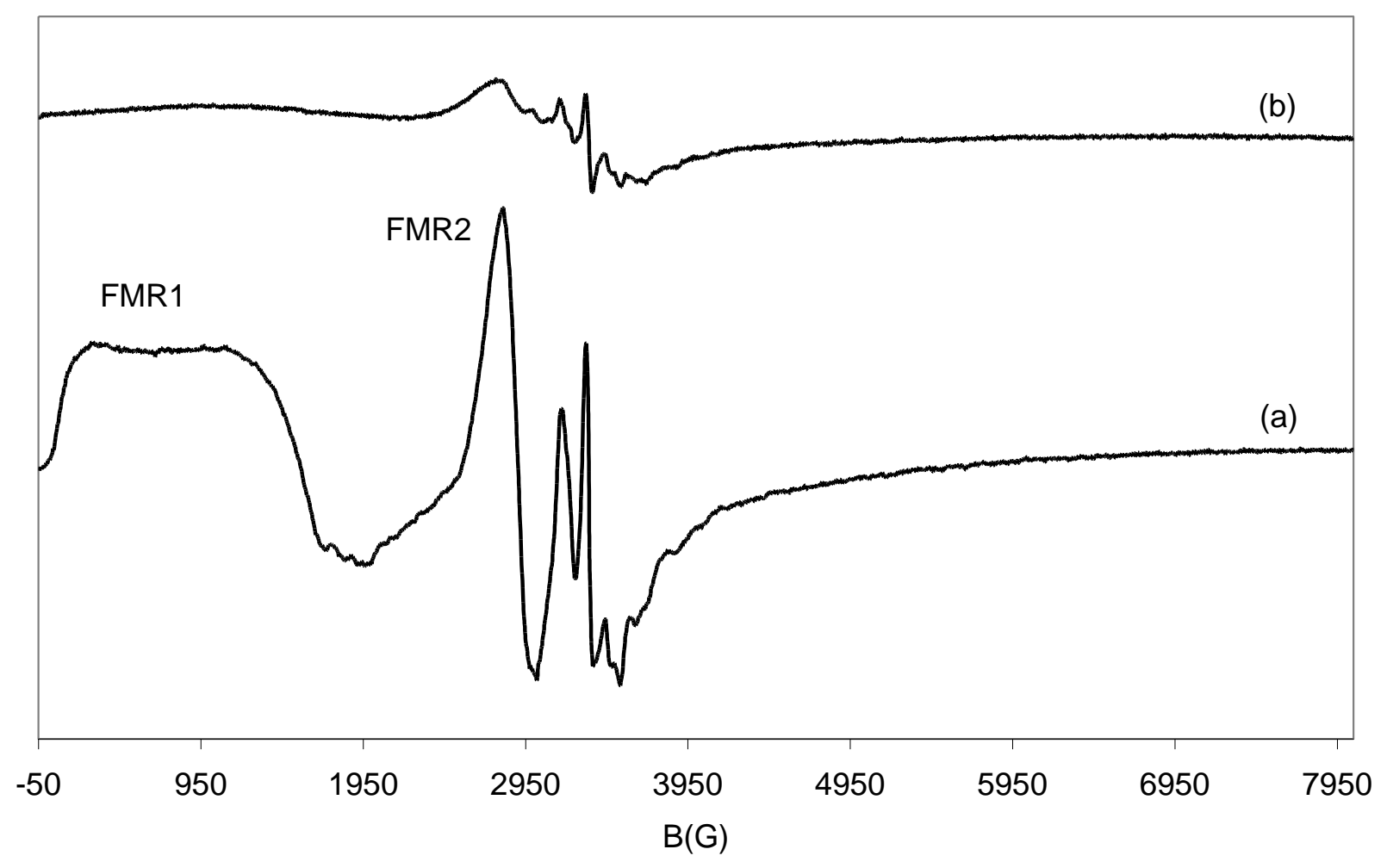


Fig.5
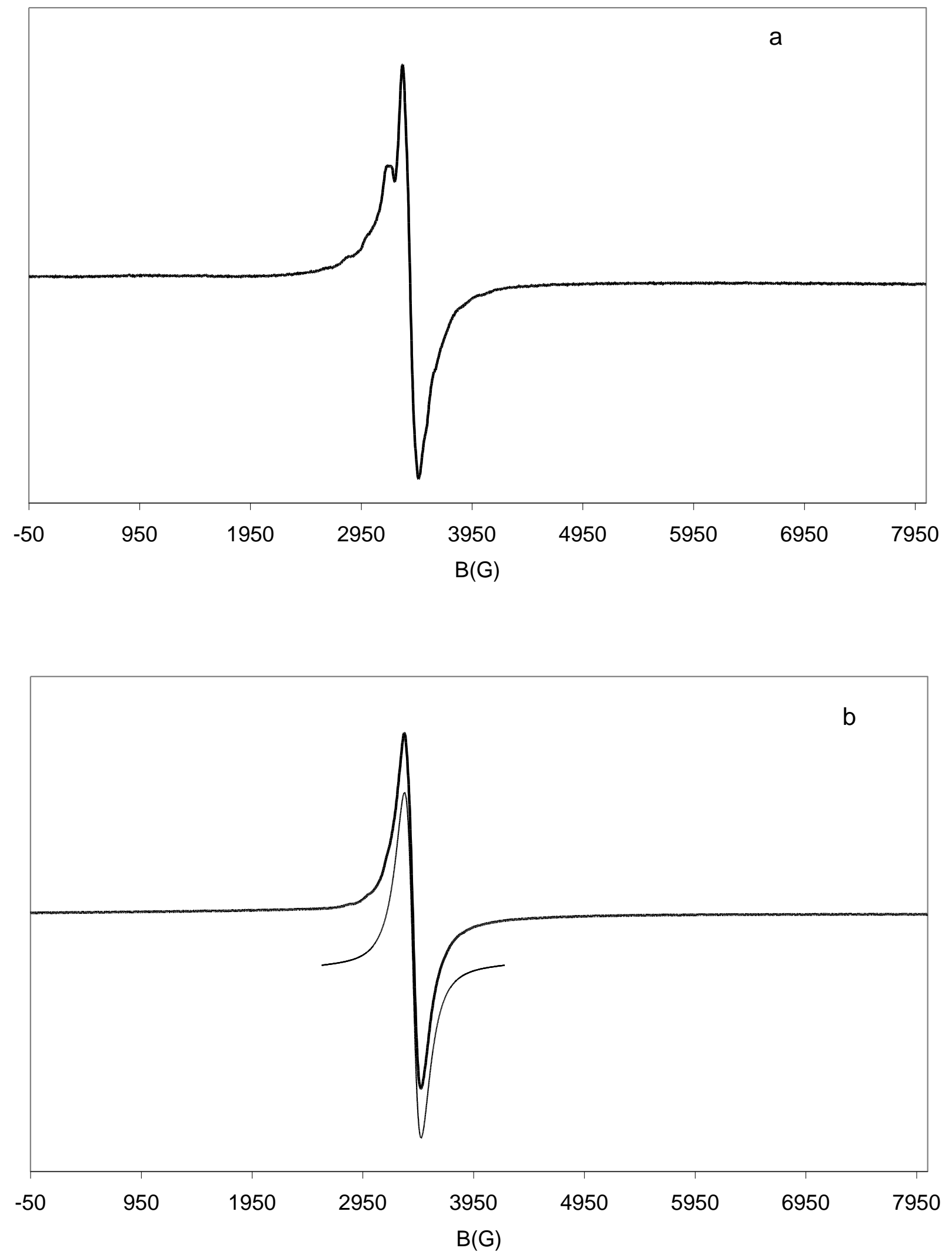
Fig.6

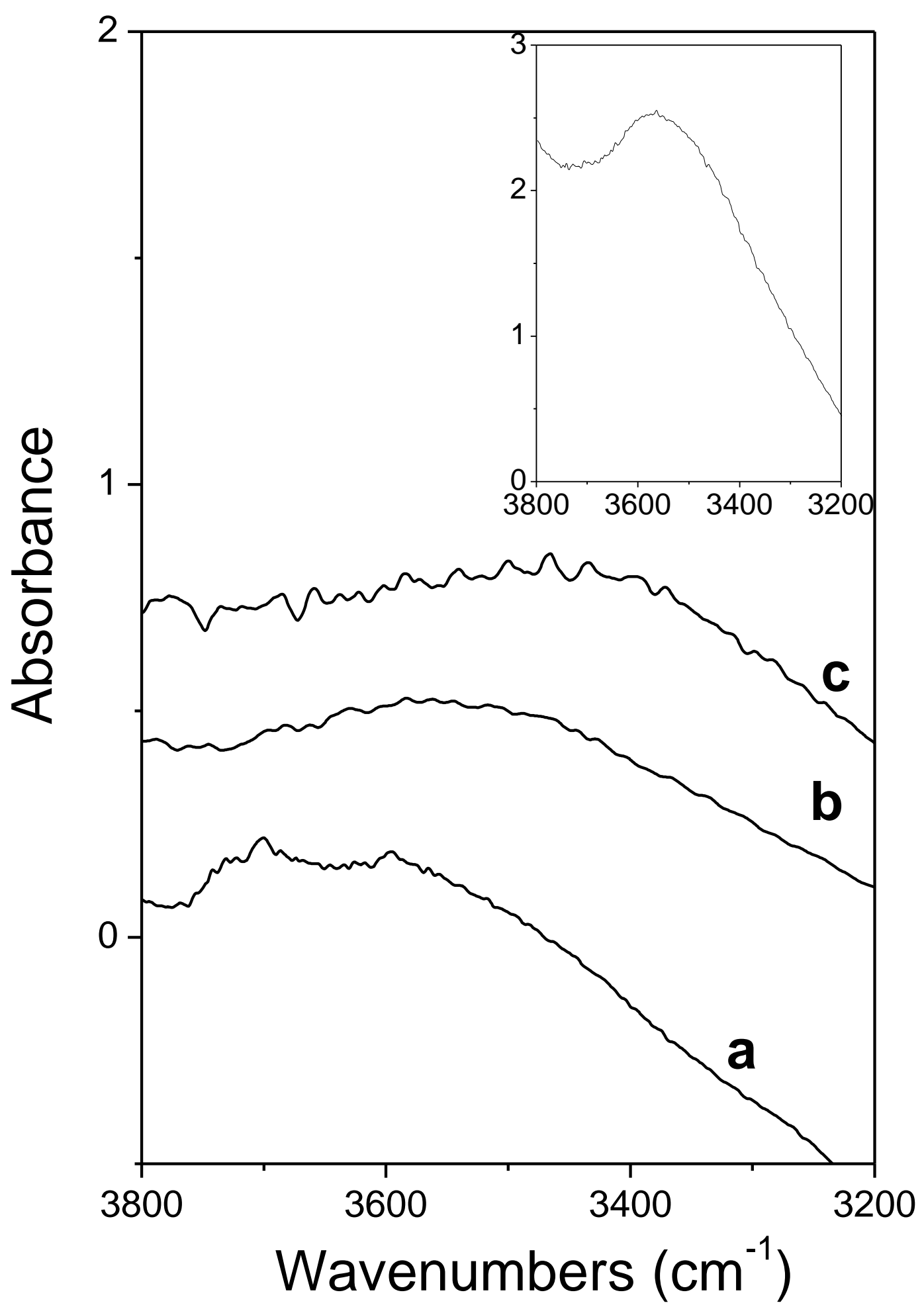


Fig.7
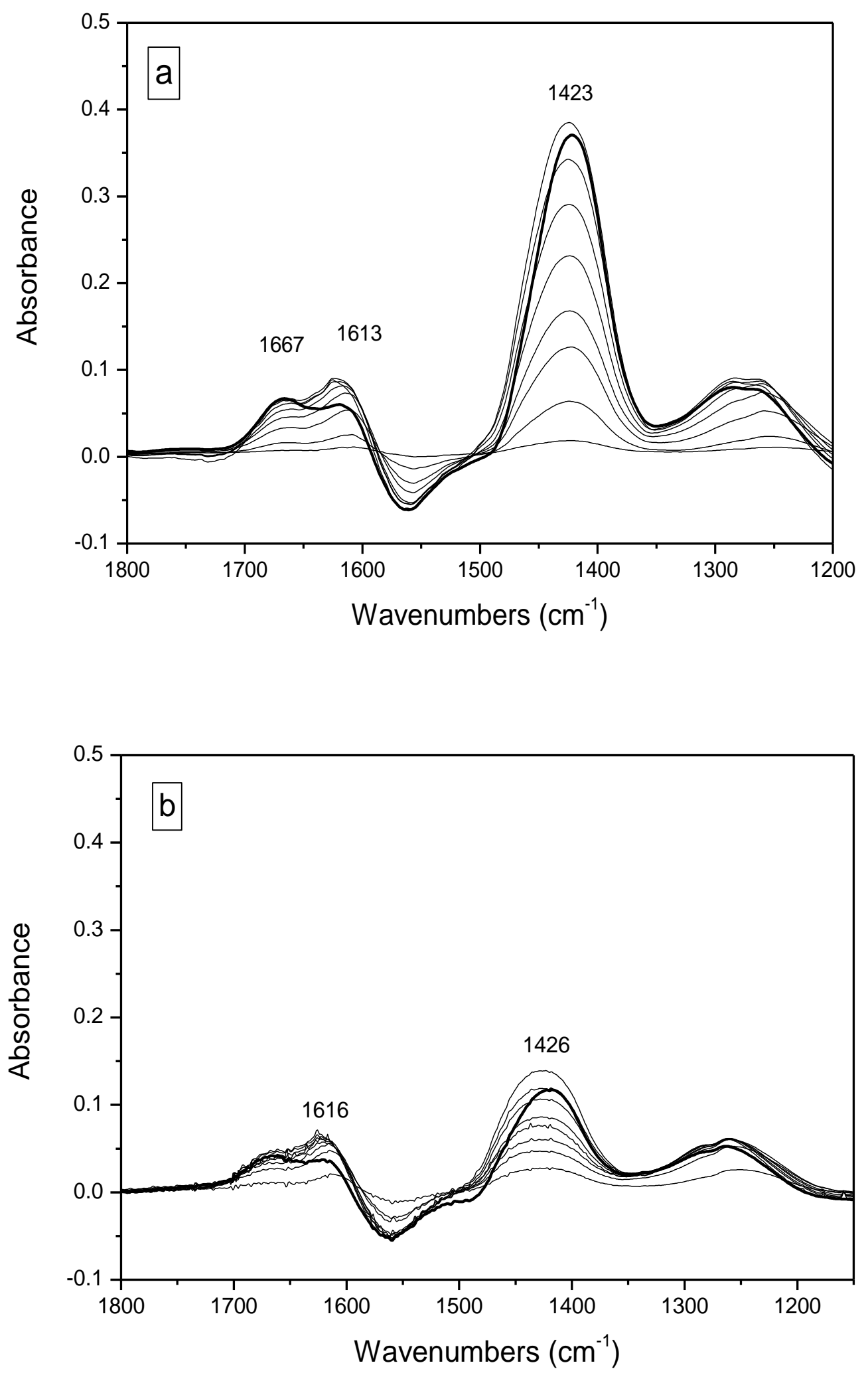
Fig.8
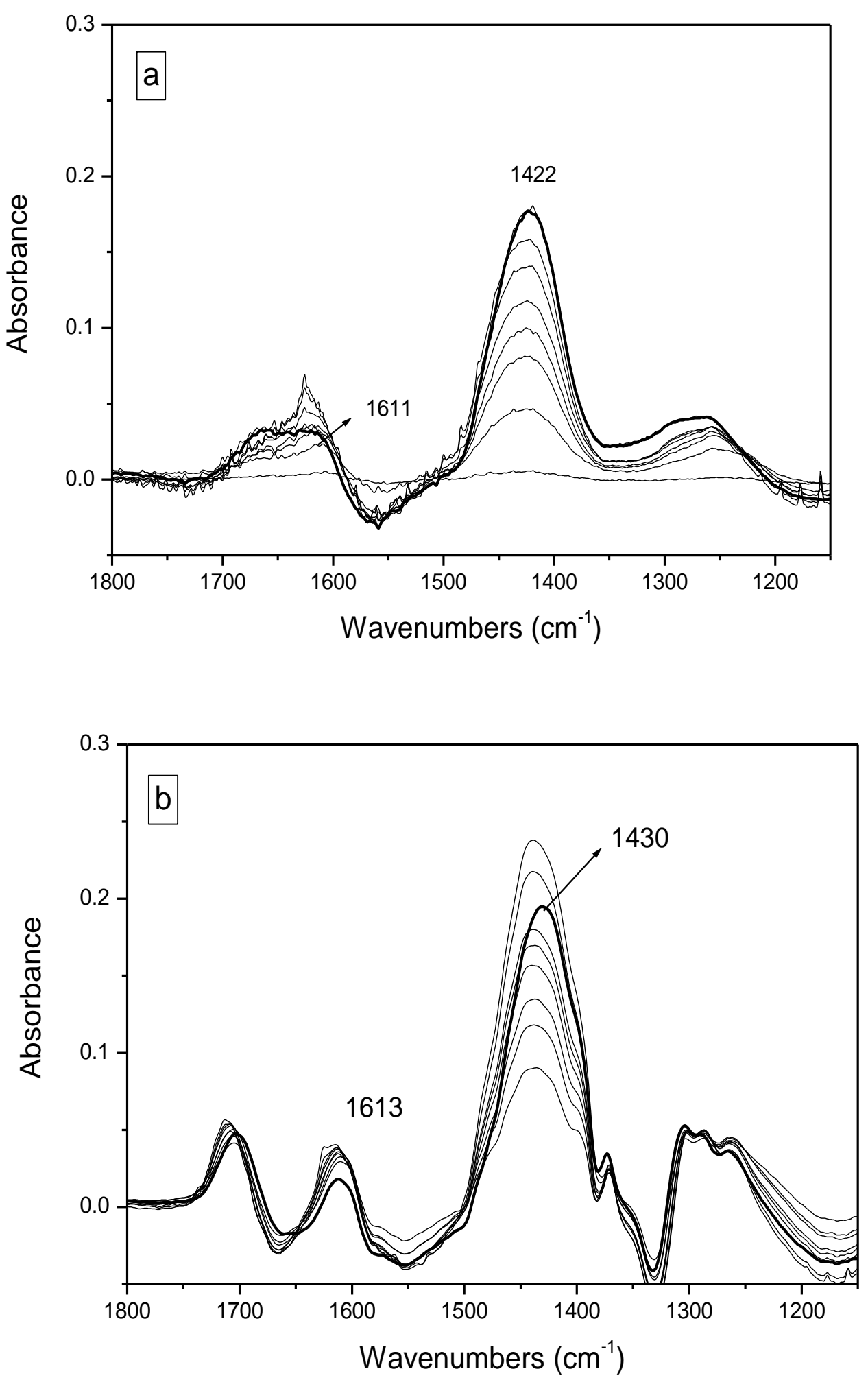
Fig.9
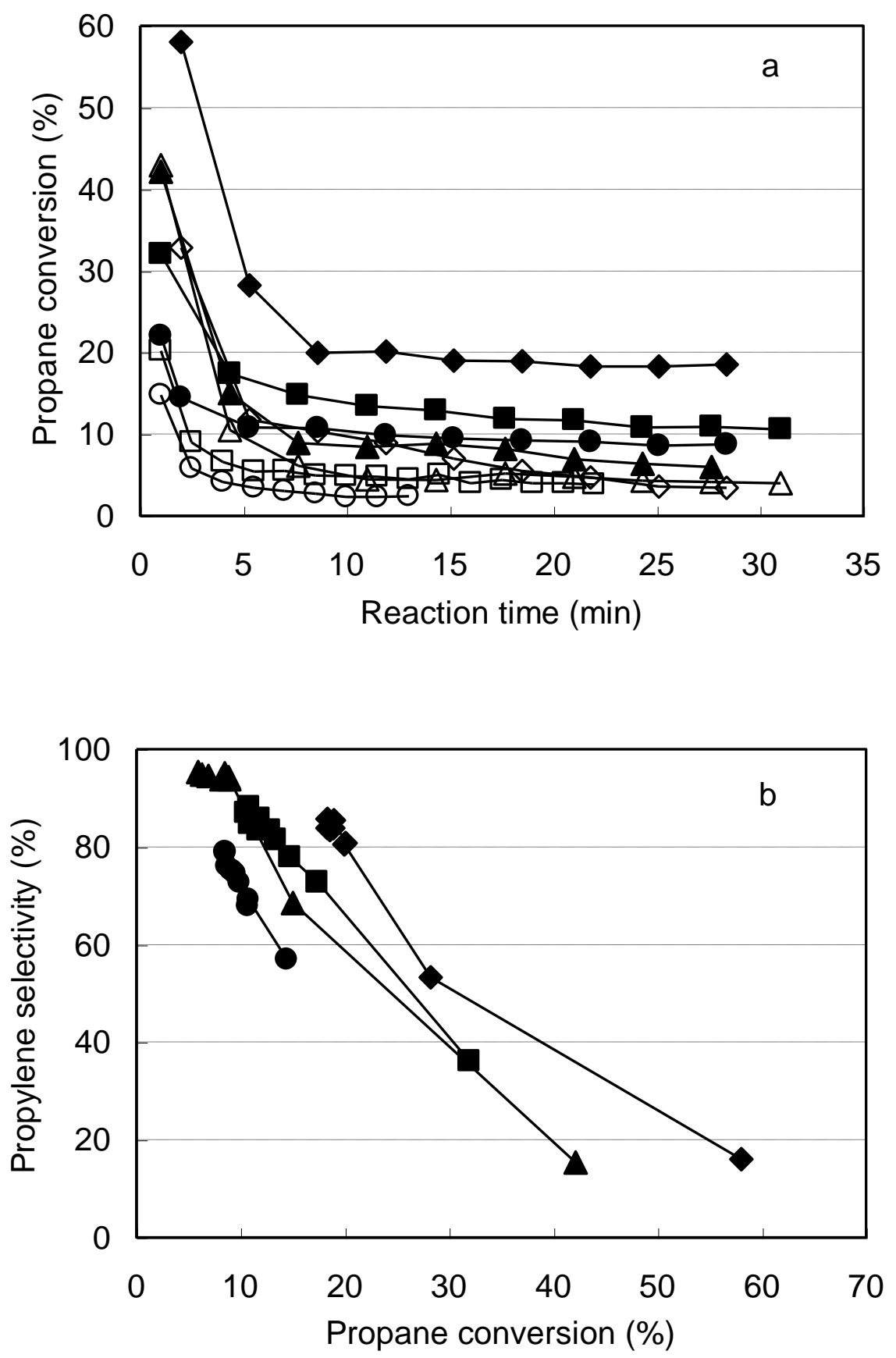
Fig. 10

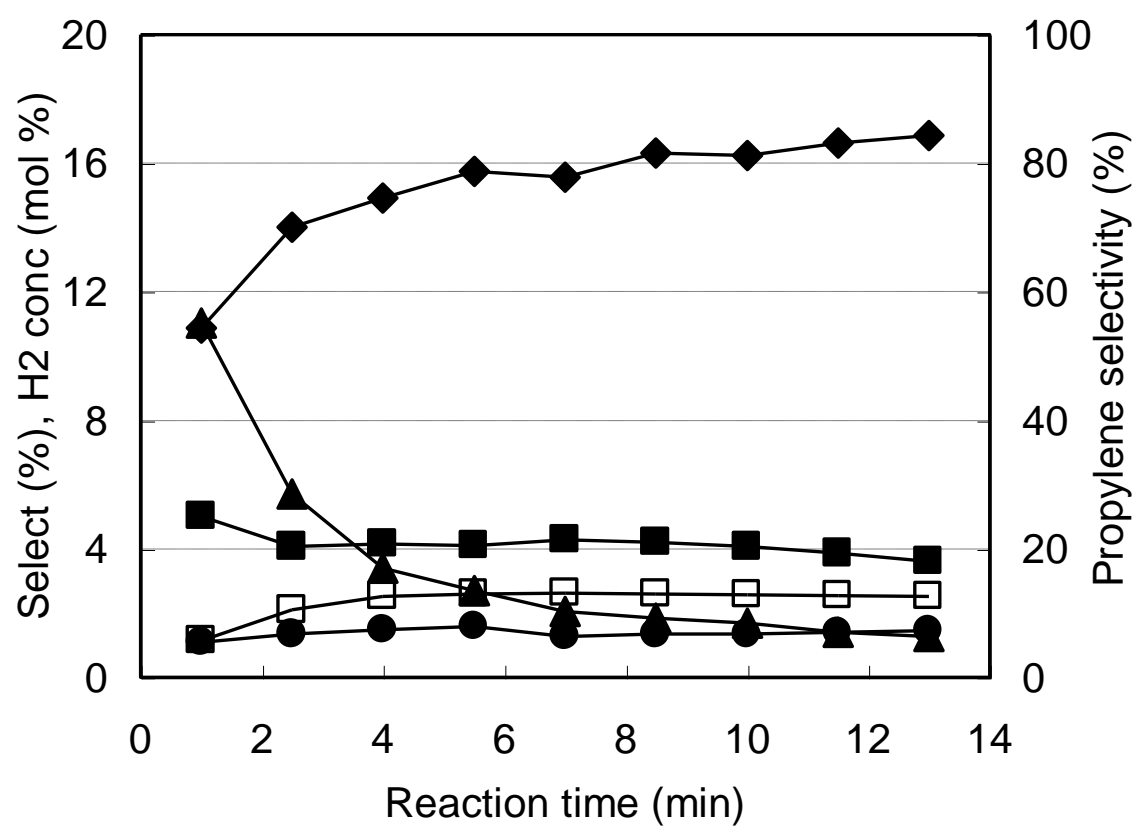


Fig. 11

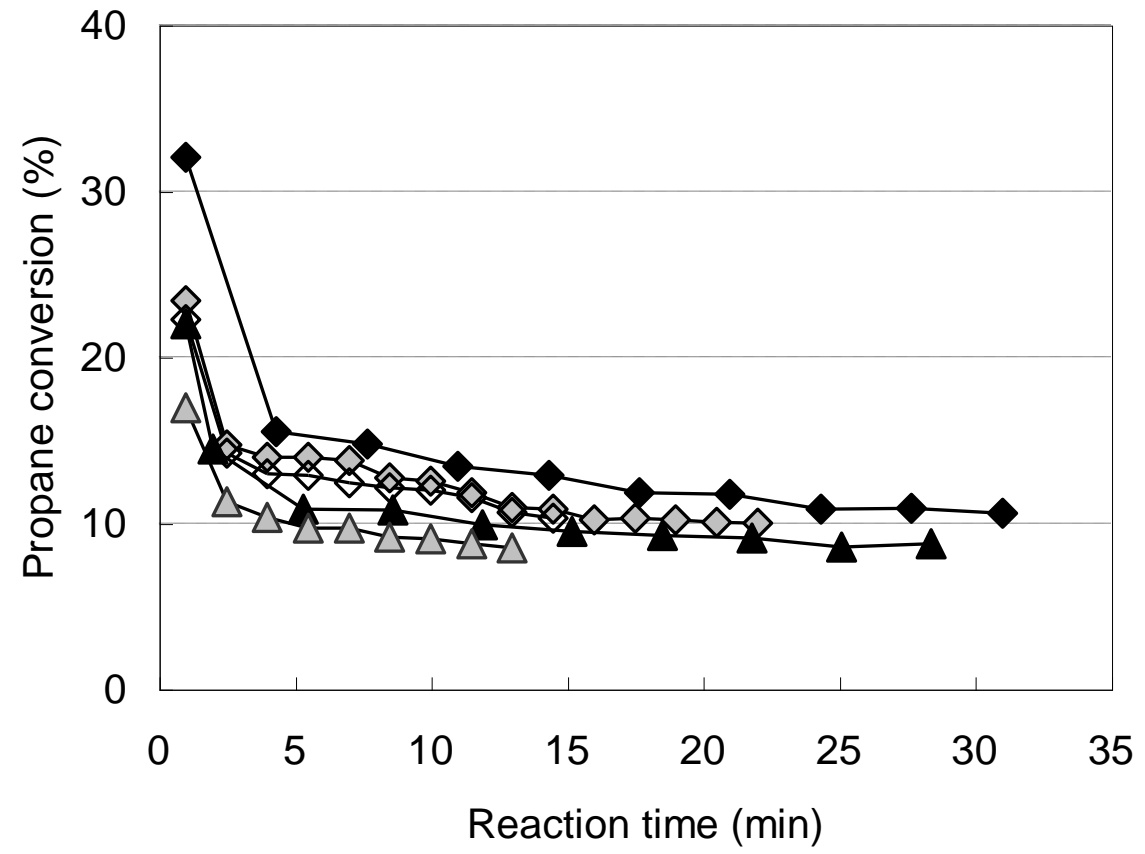


Fig. 12
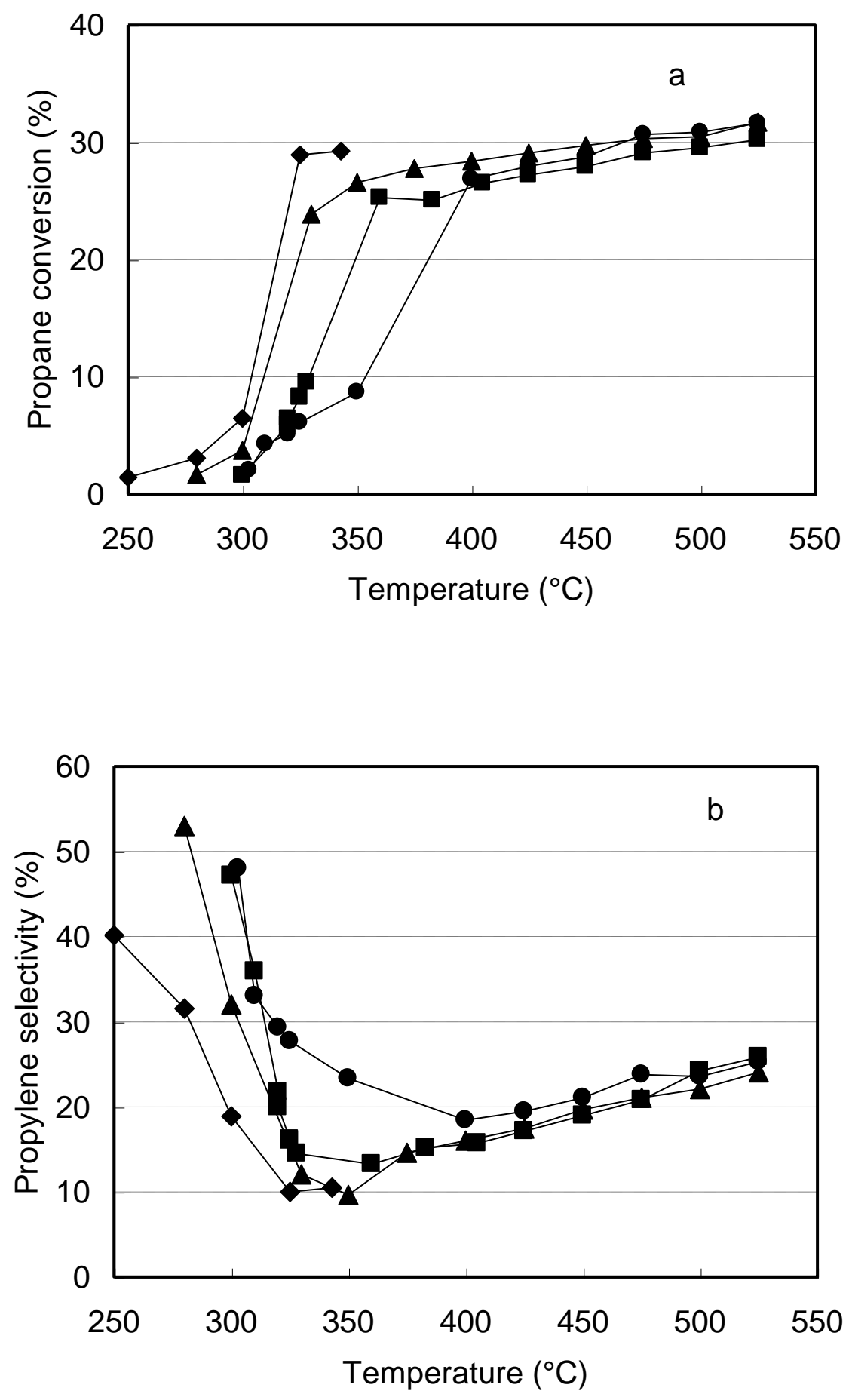
Fig. 13

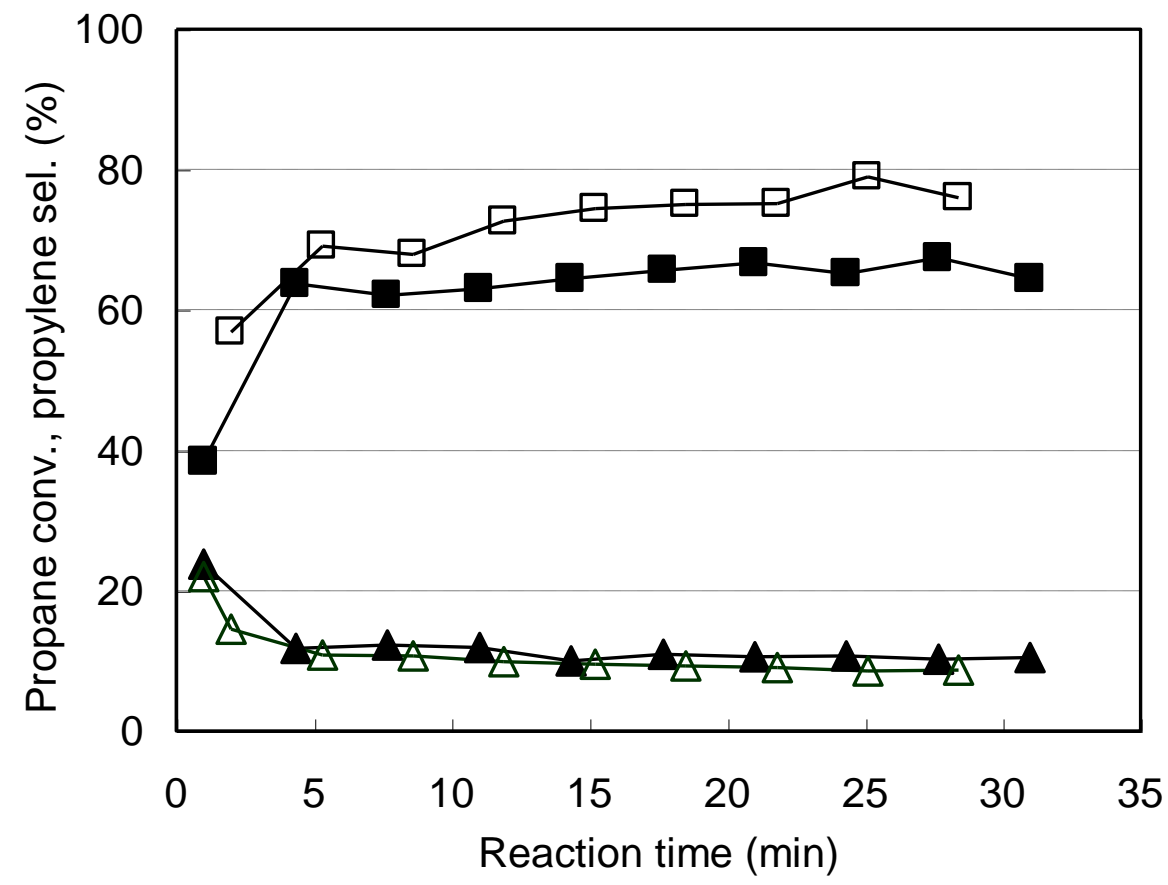


Fig.14

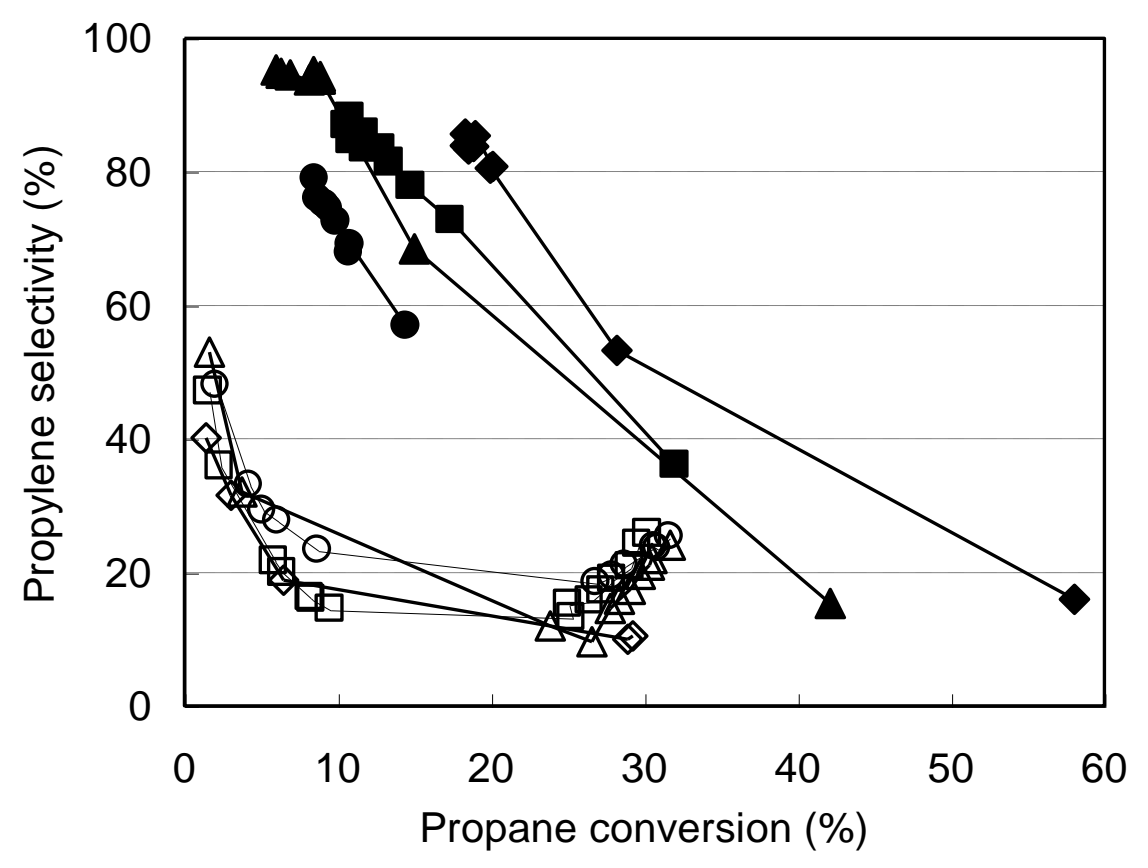

